\title{
The Social Contract with Endogenous Sentiments*
}

\author{
Matteo Cervellati
}

\author{
Joan Esteban
}

\author{
Laurence Kranich
}

\author{
March 2007
}

\begin{abstract}
Moral values influence individual behavior and social interactions. A specially significant instance is the case of moral values concerning work effort. Individuals determine what they take to be proper behaviour and judge the others, and themselves, accordingly. They increase their esteem - and self-esteem - for those who perform in excess of the standard and decrease their esteem for those who work less. These changes in self-esteem result from the self-regulatory emotions of guilt or pride extensively studied in Social Psychology. We examine the interactions between sentiments, individual behaviour and the social contract in a model of rational voting over redistribution where individual self-esteem and relative esteem for others are endogenously determined. Individuals differ in their productivities. The desired extent of redistribution depends both on individual income and on individual attitudes toward others. We characterize the politico-economic equilibria in which sentiments, labor supply and redistribution are simultaneously determined. The model has two types of equilibria. In "cohesive" equilibria, all individuals conform to the standard of proper behaviour, income inequality is low and social esteem is not biased toward any particular type. Under these conditions equilibrium redistribution increases in response to larger inequality. In a "clustered" equilibrium skilled workers work above the mean while unskilled workers work below. In such an equilibrium, income inequality is large and sentiments are biased in favor of the industrious. As inequality increases, this bias may eventually overtake the egoistic demand for greater taxation and equilibrium redistribution decreases. The type of equilibrium that emerges crucially depends on inequality. We contrast the predictions of the model with data on inequality, redistribution, work values and attitudes toward work and toward the poor for a set of OECD countries.
\end{abstract}

Keywords: Social Contract, Endogenous Sentiments, Voting over Taxes, Moral Work Values, Redistribution, Inequality, Politico-Economic Equilibrium.

JEL Classification: D64, D72, Z13, H3 and J2

\footnotetext{
${ }^{*}$ We are very grateful to Tim Besley, Melvyn Coles, Armin Falk, Eliana La Ferrara, Humberto Llavador, Kalle Moene, Sevi Mora, Debraj Ray, Uwe Sunde and audience at UPF Barcelona, Bocconi Milan, Bologna, Bogazici, Birmingham, Carlos III de Madrid, CORE, IAE Barcelona, Ille Baleares, Queens, Salamanca, Siena and Stockholm. We thank Javier Valbuena for excellent research assistantship. Financial support from the Polarization and Conflict Project CIT-2-CT-2004-506084 funded by the European Commission-DG Research Sixth Framework Programme, Barcelona Economics (CREA), CICYT grant no. SEJ2006-00369, and the Instituto de Estudios Fiscales are gratefully acknowledged. Contacts: Cervellati: University of Bologna, IAE Institut d'Analisi Economico and IZA Bonn, cervellati@spbo.unibo.it. Address: Strada Maggiore 4540126 Bologna, Italy. Esteban: IAE Institut d'Analisi Economico, joan.esteban@uab.es. Address: CSIC, Campus de la UAB, 08193 BellaterraBarcelona, Spain. Kranich: University at Albany, SUNY, lkranich@albany.edu. Address: 1400 Washington Avenue, Albany, NY 12222, USA.
} 


\section{Introduction}

Moral values are important determinants of individual behavior and of social interactions. Deviations from moral standards produce self-regulatory emotions of guilt or pride, extensively studied in Social Psychology. Guilt and pride affect both self-esteem and the esteem or empathy for others: our sentiments. These psychological reactions are termed self-regulatory because they induce compensating changes in our behavior. ${ }^{1}$ The premise of this paper is that once moral values are considered then different sentiments may affect individual behaviour and the concern for others thereby leading to the support of alternative policies or social institutions. Conversely, since policies or institutions, the social contract, generally affect behaviour, they can influence sentiments. Therefore, morally induced sentiments, individual behaviour and political choices must be treated jointly.

To investigate this reciprocal relationship between moral values, sentiments and the social contract, we consider the issue of voting over fiscal redistribution with endogenous labour supply à la Meltzer and Richard (1981) (henceforth MR). As exposited there, the explanation for redistributive taxation holds that the outcome under majority rule voting reflects the preferences of the median voter. ${ }^{2}$ In contrast to the purely egoistic model of MR, we assume that agents are altruistic and that sentiments are endogenous. ${ }^{3}$ We consider agents with moral standards or values pertaining to work, regarding hard work as good and laziness as bad. This moral judgement on the observed behaviour influences the esteem that each individual has for the others and hence the attitudes toward redistribution. ${ }^{4}$

Formally, we provide a model in which a continuum of agents differ in their productivities. For simplicity, we assume there are two types of individuals, skilled and unskilled, with the latter comprising the majority of the population. Each agent supplies labour in return for a competitive wage, and earnings are subject to a purely redistributive proportional tax the proceeds of which are distributed uniformly as a per capita transfer. Individual utility has two components: private and social. The private utility depends on consumption and leisure as well as, consistently with the own work values, the self-worth deriving from the perception of oneself as industrious or lazy. The social component consists of the weighted well-being of the others. We distinguish between the weight given to the aggregate well-being of the others relative to the own private utility - that is, the empathy or esteem for the other - and how this aggregate weight is allocated among the different individuals - that is, the esteem felt for each onedepending on whether we consider them as industrious or lazy.

The endogenous variables in our model - labour supply, sentiments and taxes - are determined as follows. Given their sentiments and the tax schedule, agents make labour supply

\footnotetext{
${ }^{1}$ The findings in social psychology and sociology on the relationship between moral standards and sentiments/emotions is discussed in more details in section 2 .

${ }^{2}$ It is now well recognized that the implication of this classical theory that higher income inequality leads to greater equilibrium redistribution fails to hold in practice. Perotti (1996) reports the lack of any significant correlation. Rodriguez (1999) fails to find evidence within US states. In line with the discussion we present in Section 6, some authors, like De Mello and Tiongson (2006) also find a possibly nonmonotonic relationship in the OECD countries. Finally Milanovic (2000), despite finding a negative correlation between inequality and redistribution, finds no evidence that the median voter receives income gains from fiscal redistribution. See also Bénabou (1996 and 2000) for an extensive surveys of the evidence.

${ }^{3}$ To the best of our knowledge, the only theoretical paper to address the political economy of taxation with altruistic agents is Kranich (2001). Snyder and Kramer (1988) and Alesina and Angeletos (2005) study the choice of redistribution when individuals care about fairness.

${ }^{4}$ The role of (work) values on voting behaviour has been recognised for a long time (see Kinder and Sears (1988)). Recent empirical investigations of individual preferences for taxation in economics provide support the view that voters preferences are social and driven by moral values. See Luttmer (2001), Fong (2001) and Alesina and La Ferrara (2005), among others. In particular Corneo and Grüner (2002) find that work values are key to explaining individual preferences for redistribution. These results are in line with the data from the World Values Survey as discussed in Section 6.
} 
decisions. Since there is a continuum of individuals, the labour supply decision has no impact on the well-being of the others and is therefore made on the basis of the private preferences only. Then, having determined the labour supplies, we assume agents evaluate such behaviour relative to this standard, increasing their relative esteem (or self-esteem) for those who exceed the standard and decreasing their esteem for those who fail to meet the standard. Here, we take the standard to be the average or mean labour supply. Finally, given their sentiments individuals vote over redistribution anticipating the labour supply effects of taxation. Taxes have an economy-wide effect and hence the choice of taxation is determined on the basis of the social as well as the private components of individual preferences. Since a majority of agents are unskilled, the median tax policy will be that preferred by an unskilled worker.

A politico-economic equilibrium of our model consists of a vector of labour supplies, sentiments and tax policy such that each is optimal given the other components and all such variables are compatible. There are two types of politico-economic equilibria in our model. In a cohesive equlibrium all individuals conform to the ethical norm and supply equal quantities of labour. In equilibrium there is an inverse relation between the level of altruism (empathy for others) and individual skill level. Furthermore, each individual's esteem for others is allocated across the two types of agents in proportion to their population. Hence, it is not biased in favor or against either type. Finally, the chosen tax rate is "high" relative to the second type of equilibrium. In contrast, in a clustered equilibrium, society is divided into two groups or clusters. One consists of the most productive individuals, who work above the mean and garner maximal esteem, while the other consists of the least productive individuals, who work below the mean and earn little social esteem. ${ }^{5}$ In a clustered equilibrium the chosen tax rate might be lower than in a cohesive society and agents' sentiments are biased against the poor, that is, the productive individuals receive a disproportionately large share of social esteem. Whether an economy becomes cohesive or clustered depends on the degree of inequality of pre-tax income or skill level. If inequality is below a critical level then cohesion results, whereas higher inequality leads to social clustering.

There are four main implications of our theory: $(i)$ Equilibrium degree of redistribution: it needs not be monotonic with respect to inequality. Throughout the range of cohesive equilibria, higher inequality leads to higher redistribution. This positive relation is preserved at higher - but moderate - levels of inequality. However, at some critical value of inequality the bias in sentiments in favor of the skilled becomes sufficiently strong so that any further increase in inequality leads to a decrease in redistribution. It follows that we might observe one society with low pre-tax earnings inequality - because it has remained cohesive - choosing to redistribute more than a society with larger inequality that is clustered. Therefore, the model does not support the unconditional prediction of a negative relationship between inequality and redistribution. ( $i i)$ Distribution of labour supply: for low levels of inequality we should observe little or no dispersion in labour supply, but for high levels we should observe a widening gap between the labour hours of skilled and unskilled workers. (iii) Work motivation and skills: in each equilibrium individual skill levels are inversely related to individual moral work motivation (associated to a lower selfesteem induced by guilt). Hence the unskilled/poor workers face larger moral work pressure than the skilled. ( $i v)$ Social consideration: in cohesive economies individual altruism will be uniformly allocated over the entire population, whereas in clustered economies higher inequality will lead to increasing bias in favor of the rich and against the poor. Hence, attitudes toward the poor are more likely to be favorable in economies with low inequality and critical when inequality is high. We discuss these implications by comparing cross-country data for a set of OECD countries. Using both objective and survey data, we compare inequality, redistribution, labour supply and attitudes toward work and toward the poor. While the latter (attitudes) are

\footnotetext{
${ }^{5}$ If there were more than two skill levels, then it is possible there would exist a third cluster in equilibrium, where those in the middle group would conform to the standard. We discuss this possibility in more detail in Section 6 .
} 
clearly difficult to measure, nevertheless, and with due caution, we find that the data appear broadly in line with each of the predictions.

This paper is related to several literatures/issues. In addition to the topic of voting over taxes, the paper also contributes to the literature on endogenous preferences and the economic analysis of socio-psychological factors and moral norms. Elster (1989) argues that effort provision is crucially influenced by work norms. In our model, the violation of the work norms produces psychological costs. Following the Social Psychology literature on self-regulatory emotions, individuals experience the self-conscious emotions of guilt and pride as they fall short or go beyond what their moral values dictate as proper behavior. These emotions serve a selfregulatory function: the feeling of guilt for violating the moral standard increases the moral pressure and induces an individual to undertake reparatory actions. As a result, moral values and economic incentives jointly determine individual behaviour. Several important contributions, most notably by Bénabou (2002) and Bénabou and Tirole (2002 and 2003), have investigated the related concepts of self-confidence and the role of individual beliefs for self-regulation. Differently from these contributions, however, our focus is on the role of moral values in shaping self-esteem and, crucially, esteem for others rather than investigating the role of self-confidence and beliefs under uncertainty or lack of information on own characteristics [more in Section 2].

The papers by Moffit (1983) and Besley and Coate (1992) also study the role of moral values and of moral persuasion. They consider the case in which there are social norms against living on transfers and agents face the threat of 'welfare stigma'. Lindbeck, Nyberg, and Weibull (1999) have extended this analysis to include voting over welfare benefits. There, individuals can choose between working full-time or being unemployed and receiving a subsidy. The "psychic costs", i.e., the stigma of living on welfare depends on the prevalence of such behaviour. Hence, the observed behaviour of others influences one's attitude toward deviating from the norm, and the cost of deviating may affect the decision to do so. Our model also considers the "psychic costs" of deviating from the social norm. However, it departs from the work of Lindbeck, Nyberg, and Weibull (1999) in two essential ways. First, we focus on the intensity of work effort, which in our model varies continuously, versus the discrete choice of working full-time or living on transfers. ${ }^{6}$ Second, it is crucial in our model that moral judgements befall on others as well as oneself. It is the contrast between "normal" behaviour and observed behaviour what influences esteem. ${ }^{7}$ This allows us to study how inequality and moral values shape social esteem and, accordingly, preferences for redistribution and the social contract. ${ }^{8}$

Finally, the paper also contributes to the recent debate on the interpretation of the observed differences in "social contracts", in particular between the US and the EU. ${ }^{9}$ Several papers

\footnotetext{
${ }^{6}$ Lindbeck et al (1999) consider the case of full work vs full unployment and the moral component of the utility function is additively separable (thus ruling out any influence on the substitution of labour for consumption). For them this is a lump-sum psychological cost. A large body of research, however, document interactions between economic and non economic incentives. Deci et al (1999) showed definitively that tangible rewards undermine intrinsic motivation. Kehr (2004) finds that this is the case unless the extrinsic motivation do not deactivate task enjoyment. Falk and Fehr (2002, p. 713) make the point that "the convention to take the disutility of effort as exogenously given induces economists to disregard potential determinants of the (dis) utility of effort."

${ }^{7}$ Brekke, Kverndokk, and Nyborg (2003) and Akerlof and Kranton (2004) also consider cases in which agents derive utility from conforming with a social norm or belonging to a group. The former considers a similar question of voluntary contributions to a public good, and the latter investigates group identification and identity. Both focus on self-image rather than passing moral judgement on others.

${ }^{8}$ Notice also that the aim of the paper is not to study the emergence and/or persistence of work values but rather to investigate their economic and political implications. See Lindbeck et al. (2006) for an economic analysis in which parents are norm sender and instill in their children work norms which are sustained by guilt. See also Lindbeck, Nyberg, and Weibull (2003) and Bisin and Verdier (2004) and for recents studies of the persistence and evolution of work ethics and the welfare state.

${ }^{9}$ The comparison of the US versus EU social contracts has generated a significant amount of literature (some of which is discussed below). We refer the interested reader to the extensive analysis in Alesina and Glaeser (2004).
} 
explain the differences as resulting from the existence of multiple equilibria. Generally, the explanations have focused on real or perceived differences in income mobility, on the relative role of luck versus effort in determining future income or the role of capital market imperfections. Bénabou (2000) show that capital market imperfections and inequality (in an economy with differential political power) may lead to multiple equilibria. ${ }^{10}$ Hassler, Rodriguez Mora, Storesletten and Zilibotti (2003) characterize multiple equilibria in a dynamic voting model in which individuals expectations about redistribution and investment in education support each other in equilibrium. The role of beliefs on the role of luck and effort for income production was investigated in Piketty (1995), who show that they can be self-fulfilling and Alesina and Angeletos (2005) who, considering individuals with preferences for fairness, show that voting over taxes may lead to multiple equilibria. Bénabou and Tirole (2005) explore the cognitive hypothesis that individuals may censor evidence on social mobility that conflicts with their perception of reality and study the implications for redistributive politics. The emerging overly optimistic beliefs tend to moderate support for redistribution. ${ }^{11}$ Our contribution is complementary to this strand of literature and it does not rely on real or perceived differences in mobility, asymmetric information or imperfections in capital markets. In our case the different types of equilibria are associated with different endogenously determined attitudes toward others and oneself. The ultimate determinant of which type of equilibrium will prevail is the degree of pre-tax inequality.

The paper is organized as follows. Section 2 describes the basic model, introduce the determination of sentiments and characterizes optimal labour supply. Section 3 examines the emergence of socioeconomic equilibria conditional on the degree of inequality and redistribution. Section 4 studies preferences over redistribution and characterizes the politico-economic equilibria in which taxes, sentiments and labour supply are simultaneously determined. In Section 5 we specify functional forms which allow us to analytically characterize the different equilibria and to study in detail the relationship between inequality, social cohesion and redistribution. Section 6 discusses the testable implications of the model and contrasts them with the available evidence for a set of OECD countries. Finally, Section 7 discusses the role of the assumptions and the robustness of the results. Proofs are relegated to the Appendix.

\section{The Model}

\subsection{Set up}

There are two commodities, consumption $c$ and labour $L$, and a continuum of agents on $[0,1]$. Individuals are of one of two types, skilled or unskilled, distinguished by their productivities/wage, $\beta_{s}$ and $\beta_{u}$, respectively, where $\beta_{u}<\beta_{s}$. Average productivity is denoted $\beta$. Let $\pi$ denote the proportion of individuals of type $s$. We assume $\pi<\frac{1}{2}$, reflecting the fact that a majority of agents are unskilled. The amount of effective labour supplied by an individual with productivity $\beta_{i}$ is $\beta_{i} L_{i}$, for $i=u, s$. We assume output depends linearly on effective labour so that

$$
Y=(1-\pi) \beta_{u} L_{u}+\pi \beta_{s} L_{s}
$$

Labour income is subject to a purely redistributive linear income tax described by the pair $(\tau, T)$, where $\tau \in[0,1]$ is the constant marginal tax rate and $T$ is a budget balancing uniform

\footnotetext{
${ }^{10}$ See Bénabou (1996) for an excellent and comprehensive survey of the literature on the different channels through which capital market imperfections create inefficiencies in unequal societies.

${ }^{11}$ Bénabou and Ok (2001) present a model in which the (egoistic) poor face upward mobility prospects; they characterize conditions under which the poor would rationally vote for a moderate level of redistribution. Corneo and Grüner (2000) and Grüner and Schils (2006) also have investigated the existence of (social) limits to the demand for redistribution.
} 
per capita transfer. That is,

$$
T(\tau)=\tau\left[(1-\pi) y_{u}+\pi y_{s}\right] \equiv \tau y,
$$

where $y_{i}=\beta_{i} L_{i}$ is the pre-tax income of individual $i$ and $y$ is average income. Hence, individual after-tax disposable income is

$$
y_{i}^{d}=(1-\tau) y_{i}+T=(1-\tau) \beta_{i} L_{i}+T,
$$

which we assume is entirely consumed.

The overall welfare evaluation of an individual of type $i$, which we denote $V_{i}$, is composed of the sum of two components, private utility, $v_{i}$, and social utility, $w_{i}$. The latter captures the effect of $i$ 's relative empathy or concern for others on its well-being and is explained in detail below. Hence, we have

$$
V_{i}=v_{i}+w_{i}
$$

Private utility. Focusing first on $v_{i}$, we assume, as in Lindbeck et al. (1999), that private utility depends on consumption, $c_{i}$, and leisure, $l_{i} \in[0, \bar{L}]\left(L_{i}=\bar{L}-l_{i}\right)$, as well as on the parameter $\varphi_{i}$ measuring self-worth or self-esteem. Thus, we write

$$
v_{i}=v\left(c_{i}, l_{i}, \varphi_{i}\right) .
$$

We assume $v$ is strictly increasing and concave, that consumption and leisure are both normal goods, and that $v_{c l}>0$. We also assume initially that $v$ satisfies the standard Inada conditions. ${ }^{12}$ In the sequel, the parameter $\varphi_{i}$ will be determined endogenously through social interaction, but for now we take it as given. We denote $\boldsymbol{\varphi} \equiv\left(\varphi_{u}, \varphi_{s}\right){ }^{13}$

Social utility. Turning to the social or altruistic component of (4), we assume $w_{i}$ consists of a weighted sum of the private utilities of the other agents. Let $\alpha_{i, j} \geq 0$ denote the relative esteem or concern felt by an individual of type $i$ towards one of type $j$. We denote the vector of agent $i$ 's weights by $\boldsymbol{\alpha}_{i} \equiv\left(\alpha_{i, u}, \alpha_{i, s}\right)$ and the full array of weights by $\boldsymbol{\alpha} \equiv\left(\boldsymbol{\alpha}_{u}, \boldsymbol{\alpha}_{s}\right)$.

The social component of overall utility is thus given by

$$
\begin{aligned}
w_{i} & =(1-\pi) \alpha_{i, u} v_{u}+\pi \alpha_{i, s} v_{s}= \\
& =\alpha_{i}\left[\left(1-\sigma_{i}\right) v_{u}+\sigma_{i} v_{s}\right] \equiv \alpha_{i} \widetilde{w}_{i},
\end{aligned}
$$

where $\alpha_{i}$ is individual $i$ 's (average) social concern

$$
\alpha_{i} \equiv(1-\pi) \alpha_{i, u}+\pi \alpha_{i, s}
$$

with $\alpha_{i} \in[0,1]$, and

$$
\sigma_{i} \equiv \frac{\alpha_{i, s} \pi}{\alpha_{i}}
$$

is the share of $i$ 's social concern allocated to the group of type $s$ agents. ${ }^{14}$

Using this notation, we can write individual total utility as,

$$
V_{i}=v_{i}+\alpha_{i} \widetilde{w}_{i} .
$$

\footnotetext{
${ }^{12}$ We assume the Inada conditions $\left(\lim _{c \rightarrow 0} v_{c}=\infty, \lim _{c \rightarrow \infty} v_{c}=0, \lim _{l \rightarrow 0} v_{l}=\infty\right.$, and $\left.\lim _{l \rightarrow \bar{L}} v_{l}=0\right)$ are satisfied in order simplify the exposition by insuring interior solutions. In fact in the second part of the paper we illustrate the working of the model by restricting attention to a quasi-linear specification of the utility function.

${ }^{13}$ Since agents differ only in their productivities, all agents of the same type will behave in the same fashion in equilibrium. Hence, in our behaviour-based theory of endogenous sentiments, we assume all such agents have the same self-esteem and esteem for others.

${ }^{14}$ Thus we exclude malevolence and we assume no agent cares more about others than it does about itself. The former is for expositional convenience. Our results only require that sentiments be bounded below. We normalize the support of individual altruism to $[0,1]$ for tractability. The qualitative results are unchanged for arbitrary upper and lower bounds $\bar{\alpha}$ and $\underline{\alpha}$, respectively, $[\underline{\alpha} \geq 0, \bar{\alpha}<\infty]$.
} 


\subsection{Moral Work Values, Endogenous Sentiments and Behaviour}

The role of moral values is a central topic in Social Psychology. Rokeach (1973) defines values as general and enduring standards that help us to "evaluate and judge, to heap praise and fix blame on ourselves and others" (p. 13). Values can be associated to, and sustained by, both social and moral enforcement mechanisms. While social norms and values are conventions that are imposed on us from the outside, moral norms are "injunctive" and result from an inner pressure to behave in a particular way. ${ }^{15}$ In this paper we focus on moral values only, specifically moral values concerning work: "work values". As Lukes (1973) notes work values are crucial in western culture which "celebrates the virtues of hard work and sacrifice. It equates idleness with sin".

Behaving or not accordingly with our moral standard has an effect on self-esteem and on the esteem we assign to others (see e.g. Crocker and Park (2003)). The impact on self-evaluation derives from the emotions of guilt and pride we feel as we fall short or go beyond what our moral norms dictate as proper behavior. According to Tangney (2002), in the Handbook of Self and Identity, "shame, guilt, embarrassment and pride serve an important self-regulatory function by providing critical feedback to the self about the self's thoughts, intentions and behavior. In the face of triumph, transgression, or error, the self turns towards the self-evaluating and rendering judgement in reference to moral standards. (...) When we violate important standards, we are inclined to experience negative self-conscious emotions, such as shame, guilt, and embarrassment. When we meet or exceed standards, we are inclined to experience pride and attendant increases in self-esteem. In this way, shame, guilt, embarrassment and pride function as an emotional barometer, providing immediate and salient feedback on our social and moral acceptability and our worth as human beings" (pp. 384-5)..$^{16}$

Guilt and pride decrease or increase our self-worth (see e.g. Tangney and Dearing, 2002). Guilt -and the corresponding change in self-esteem- has two types of consequences. On the one hand, "guilt typically leads to a reparative action."(p. 388). On the other hand, "guilt experiences...convey greater empathy for others (...) guilt and empathy go hand in hand. (...) Empirical research has shown that empathy motivates altruistic, helping behavior."(pp. 3889). ${ }^{17}$

Our modeling of the role of moral values follows this socio-psychological literature. Deviations from the moral standards produce guilt and pride, thus modifying our self-esteem. Likewise, observed deviations by others modify the worth we assign to the individual concerned. The sense of guilt and the fall in self-esteem has two consequences: the guilty person undertakes reparative actions and at the same time increases the empathy -the esteem- he feels for the others. How this empathy is allocated among the others also depends on the moral judgement on their observed behavior. We attach high (low) worth to those with positive (negative) deviations from the moral standard.

In particular, we specify work values into a work norm: average labor supply $(L)$. Working below average is considered laziness and produces guilt and negative valuations and working above produces pride and appreciation. Therefore the consequences of guilt and pride are: (i) [Allocation of social empathy] we assign a low share of social esteem (the $\sigma$ coefficient) to those we consider lazy (i.e. that fail to meet the moral standard) and a high share to the industrious

\footnotetext{
${ }^{15}$ See Cialdini, Kallgren and Reno (1991) p. 203. The terminology, however, varies with authors. Schwartz (1977) and Schwartz and Howard (1982), for instance, use the term "personal norms" for the norms based on internalized moral values which do not require external social sanction.

${ }^{16}$ See also Lamont (2000) for an extensive analysis documenting the importance of hard work as fundamental source of self-worth for manual workers in US and France.

${ }^{17} \mathrm{~A}$ large and established experimental evidence documents the self-regulative role of guilt and pride. For example, in experimental settings participants that experience guilt are much more likely to comply to moral standards. See e.g. Freedman et al. (1967), an Tangney (1995, 2002). Also, guilt and the associated changes in self-esteem, consistently relates with measures of altruism and social concern. See e.g. Eisenberg (1986), Baumeister et al (1994) and references therein.
} 
(i.e. those that exceed the moral standard); and with respect the self, (ii) [Self-esteem and social empathy] working below (above) average labor supply will decrease (increase) self-esteem (the $\varphi_{i}$ parameter) and will increase (decrease) the empathy/social consideration for the others $\left(\alpha_{i}\right)$; and finally, (iii) [Regulatory function of moral values] the decrease (increase) in self-esteem $(\varphi)$ induces a reparatory action and hence an increase (decrease) in labor supply, that is, a decrease (increase) in the marginal rate of substitution of consumption for leisure. This effect of guilt on labor supply captures the self-regulatory role of self-conscious emotions.

Formally we specify the previous points as follows: ${ }^{18}$

(i) [Allocation of social empathy] The share of social empathy $\sigma_{i}$ relative to the population share $\pi$ is equal the labor supply of this group relative to the average: ${ }^{19}$

$$
\frac{\sigma_{i}(t)}{\pi}=\frac{L_{s}(t-1)}{L(t-1)}
$$

Notice that by (8), the adjustment in $\boldsymbol{\alpha}$ is related to past performance by

$$
\frac{\alpha_{i, s}(t)}{\alpha_{i}(t)}=\frac{L_{s}(t-1)}{L(t-1)}
$$

which implies

$$
L_{j}(t-1) \gtrless L_{i}(t-1) \Leftrightarrow \alpha_{i, j}(t) \gtrless \alpha_{i, i}(t) .
$$

so that an individual of type $j$ is afforded more esteem than someone of type $i$ if and only if $j$ 's labour supply exceeds $i$ 's.

(ii) [Self-esteem and social empathy] Self-worth changes depending on one's own behavior relative to the moral standard,

$$
L_{i}(t-1) \gtrless L(t-1) \Longrightarrow \varphi_{i}(t) \gtrless \varphi_{i}(t-1) .
$$

and a drop (increase) in self-worth produced by a feeling of guilt (pride) increases (decreases) the empathy for the others $\left(\alpha_{i}\right)$, that is,

$$
\varphi_{i}(t)=g\left(\alpha_{i}(t)\right)
$$

for some strictly decreasing function $g$. Since $\alpha \in[0,1]$ we denote $\underline{\varphi}=g(1) \geq 0$ and $\bar{\varphi}=g(0)<$ $\infty .^{20}$

(iii) [Regulatory function of moral values] The repository action induced by guilt makes individuals to supply more labor -the opposite with pride- and hence the marginal rate of substitution between consumption and leisure satisfies

$$
\frac{d}{d \varphi_{i}}\left(\frac{v_{l}}{v_{c}}\right)>0
$$

Note that the sentiments of guilt and pride lead to compensatory behavior in labor supply. Pride induced by industriousness makes individuals consider leisure as "well deserved" and hence to a reduction in their labor supply (as shown in the next section).

\footnotetext{
${ }^{18}$ In the following sections we focus on steady state values and thus we will omit the explicit reference to time.

${ }^{19}$ This rule for allocation of social esteem appears natural since the work norm is defined in terms of relative labour supply. Notice that it also implies that the share of total esteem apportioned to group $s$ is proportional to that group's relative contribution to aggregate effort.

${ }^{20} \mathrm{~A}$ deeper investigation of the determinants of prosocial behaviour is outside the goal of this paper. See Bènabou and Tirole (2006) for a thorough study of this issue. For our purposes it is sufficient to consider that variations in $\varphi_{i}$ following deviations from moral standards change the relative consideration of the self towards the others.
} 
At this point, few comments on the role of moral values for work motivation are in order. Firstly, the assumed ethical rule does not take personal circumstances into account when passing judgement on others. While there are instances in which it would be natural to take personal circumstances into account, we simply take the "average work week" as the benchmark. This seems a natural starting point when modeling attitudes in large societies. ${ }^{21}$ Secondly, moral work values is but one of the relevant psychological factors which influence work effort. A large body of research in social psychology has documented a number of determinants of individual work motivation. ${ }^{22}$ Here we concentrate our attention exclusively to moral values and moral emotions. Finally notice that, following Rosemberg (1965), psychologists treat self-evaluation as multidimensional comprising notions of perceived worth both in relation with values and standards and in relation with competence in task performance. In particular, the literature distinguishes between self perception in relation with self-conscious emotions (self-esteem in relation to e.g. feelings of guilt and pride) and beliefs ("self-confidence" in relation to e.g. beliefs of being competent/incompetent). Here we restrict attention to "self-esteem" in relation to self-regulatory emotions and not "self-confidence" in relation to self-relevant beliefs. ${ }^{23}$

\subsection{Labour Supply}

Ultimately, the choice variables in our model are labour supply, $L_{i}$, and the voting decision or preferred marginal tax rate, $\tau_{i}$. ( $T$ will be determined by $(2)$ and sentiments will be determined endogenously as a result of evolution of the labour supply decisions.) In this section, however, we focus on the labour supply decision only, taking the tax policy (and sentiments) as given.

Since the size of each individual is negligible with respect to the entire economy, their choice of labour supply cannot have a direct effect on the well-being of other agents. Hence, in determining individual labour supply, only the private component of utility matters. (The social component will play a role in voting over taxes.) Thus, individual $i$ chooses its labour supply to maximize its private utility subject to the budget constraint (3), that is, $i$ solves

$$
\begin{aligned}
& \max _{L_{i}} v\left(c_{i}, \bar{L}-L_{i}, \varphi_{i}\right) \\
& \text { s.t. }\left\{\begin{array}{c}
c_{i}=(1-\tau) \beta_{i} L_{i}+T \\
L_{i} \leq \bar{L}
\end{array}\right.
\end{aligned}
$$

Substituting for $c_{i}$ and differentiating $v$ with respect to $L_{i}$, we obtain

$$
\frac{\partial v}{\partial L_{i}}=v_{c}\left((1-\tau) \beta_{i} L_{i}+T, l_{i}, \varphi_{i}\right)(1-\tau) \beta_{i}-v_{l}\left((1-\tau) \beta_{i} L_{i}+T, l_{i}, \varphi_{i}\right)
$$

\footnotetext{
${ }^{21}$ In their model of taxpayer resentment as determined by welfare stigma, Besley and Coate (1992) link the stigma to being a welfare recipient, irrespective of personal characteristics. Also Lindbeck et al (1999) assume that the psychological cost of living on unemployment benefit is not conditional on one's productivity. As discussed below the consideration of personal circunstances does not affect the qualitative results as long as individual behaviour is judged in comparison to a social standard.

${ }^{22}$ Most of these studies concern work inside organizations rather than in society at large. For example Latham and Pinder (2005) in their recent survey of theories and empirical evidence document, together with values and self-regulation, also the importance of job characteristics and design, perceived fairness on the job or task enjoyment. These results are closely related to the literature on intrinsic and extrinsic motivation (Deci (1971)). In economics this issue was first discussed by Kreps (1997) and Frey (1997). Frey and Jegen (2001) survey the theory and evidence on the role of non economic motivation. See also Falk and Fehr (2002), Gneezy and Rustichini (2001) and Murdoch (2002).

${ }^{23}$ Changes self-esteem and self-confidence tend to affect behaviour differently. For example while a reduction in self-confidence (e.g. a drop in the perceived probability of success in a task) tend to decrease effort, a reduction in self-esteem (e.g. associated to a feeling of guilt for not meeting the standard) tend to increase it. Both concepts have been recently incorporated in economic models. Most prominantly Lindbeck et al. (1999, 2006) study the role of self-regulatory emotions and moral standards while the cited works by Bènabou and Tirole study the role of self-confidence in environments with uncertainty and asymmetric information.
} 
Differentiating again, we have

$$
\frac{\partial^{2} v}{\partial L_{i}^{2}}=v_{c c}(.)(1-\tau)^{2} \beta_{i}^{2}-2 v_{c l}(.)(1-\tau) \beta_{i}+v_{l l}(.) \equiv D<0 .
$$

Since $v$ is concave and satisfies the Inada conditions, it follows that the labour supply function is implicitly defined by the first order condition $\frac{\partial v}{\partial L_{i}}=0$, or by

$$
\frac{v_{l}\left((1-\tau) \beta_{i} L_{i}+T, \bar{L}-L_{i}, \varphi_{i}\right)}{v_{c}\left((1-\tau) \beta_{i} L_{i}+T, \bar{L}-L_{i}, \varphi_{i}\right)}=(1-\tau) \beta_{i} .
$$

Expression (17) implicitly defines the optimal labour supply as a function of the relevant parameters: net wage, self-esteem and per capita transfer, i.e.,

$$
L_{i}=\lambda\left((1-\tau) \beta_{i}, \varphi_{i}, T\right) .
$$

Here, the marginal rate of substitution between consumption and labour depends on $\varphi_{i}$, thereby affecting the labour supply decision. Totally differentiating with respect to $L_{i}$ and $\beta_{i}$ in (17), we obtain

$$
\frac{d L_{i}}{d \beta_{i}}=-\frac{1}{D}(1-\tau)\left\{v_{c c}(.)(1-\tau) \beta_{i} L_{i}+v_{c}(.)-v_{c l}(.) L_{i}\right\},
$$

where $-1 / D>0$. Let us denote by $\varepsilon_{v_{c}, L}$ the elasticity of the marginal utility of consumption with respect to labour, that is,

$$
\varepsilon_{v_{c}, L}=\left[v_{c c}(.)(1-\tau) \beta_{i}-v_{c l}(.)\right] L_{i} / v_{c}(.) .
$$

Then (19) can be written as

$$
\frac{d L_{i}}{d \beta_{i}}=-\frac{1}{D}(1-\tau)\left(\varepsilon_{v_{c}, L}+1\right) v_{c}(.) .
$$

Making the assumption that $\left|\varepsilon_{v_{c}, L}\right|<1$ insures that $\frac{d L_{i}}{d \beta_{i}}>0$, or that labour supply increases with the wage.

Next, let us examine the effect a change of self-esteem on labour supply. Differentiating (17), we obtain

$$
\frac{d L_{i}}{d \varphi_{i}}=-\frac{1}{D}\left[v_{c \varphi}(.)(1-\tau) \beta_{i}-v_{l \varphi}(.)\right] .
$$

From (15) together with the first order condition (17) we have ${ }^{24}$

$$
\frac{d L_{i}}{d \varphi_{i}}<0
$$

The labour supply function so obtained, $\lambda\left((1-\tau) \beta_{i}, \varphi_{i}, T\right)$, has the property that both higher economic rewards (net wage) and increased moral pressure (associated with the perception of being lazy) increase labour effort.

${ }^{24}$ Differentiating and using the first order condition for optimal labour supply (17), we can rewrite (15) as

$$
\begin{aligned}
\frac{\partial}{\partial \varphi_{i}}\left(\frac{v_{l}}{v_{c}}\right) & =\left[\frac{1}{v_{c}}\left(v_{l \varphi}-v_{c \varphi}(1-\tau) \beta_{i}\right)\right]= \\
& =\left(\frac{v_{l}}{v_{c}} \varphi_{i}\right)\left(\frac{v_{l \varphi}}{\varphi_{i} v_{l}}-\frac{v_{c \varphi}}{\varphi_{i} v_{c}}\right)=\left(\frac{v_{l}}{v_{c}} \varphi_{i}\right)\left(\varepsilon_{v_{l}, \varphi}-\varepsilon_{v_{c}, \varphi}\right)
\end{aligned}
$$

so that (15) is equivalent to assuming the elasticity of the marginal utility of leisure with respect to self-esteem is larger than the elasticity of the marginal utility of consumption: $\left[\varepsilon_{v_{l}, \varphi}-\varepsilon_{v_{c}, \varphi}\right]>0$. 


\section{Socioeconomic Stationary Equilibria}

Having explained how labour supply is determined in response to the prevailing sentiments and how sentiments vary with labour supply, we now analyze the stationary points of this reciprocal/dynamic process. (We address the determination of the tax policy in the next section.) That is, for given $\tau$, we wish to consider combinations $(\mathbf{L}, \boldsymbol{\varphi}, \boldsymbol{\alpha})$ such that for each $i=u, s$, (a) $L_{i}$ satisfies (18) at $\varphi_{i}$, (b) $\varphi_{i}$ is invariant at $\mathbf{L}$ under the adjustment process $(13)$, (c) $\varphi_{i}$ and $\alpha_{i}$ are related according to (14), and (d) $\mathbf{L}$ and $\boldsymbol{\alpha}$ satisfy (11). Condition (c) says the levels $\varphi_{i}$ and $\alpha_{i}$ are linked according to the reciprocal relation (14), whereas (d) says the distribution of social empathy is consistent with relative performance. We refer to such a combination as a socio-economic stationary equilibrium, or SE equilibrium for short.

Notice from the assumed dynamics of sentiments (13) and from (22) that self-esteem provides a countervailing force to the complete polarization of labour supply; those with low self-worth face moral pressure to work more, and those with high self-worth have an incentive to work less. This is similar to the welfare stigma effect in Lindbeck et al. (1999) where individuals face moral pressure to work and avoid the stigma of welfare, and they receive additional utility when they accede to this moral principle. Here, since self-esteem changes in response to observed relative performance, there is a tendency to converge to an endogenous social norm concerning effort provision. Nevertheless, as we shall see below convergence is not always possible.

There can be two different types of $S E$ equilibria in which economic behaviour and sentiments are mutually compatible. In the first type, everyone conforms to the moral standard and supplies the average number of work hours. Whatever the matrix $\boldsymbol{\alpha}$ of coefficients necessary to support such behaviour, no agent will have a reason to modify its sentiments for any other agent or its self-esteem. Furthermore, since in this case all agents supply the same quantity of labour, equilibrium sentiments are such that $\sigma_{i}=\pi$, for all $i$. Hence, there is no bias or discrimination in the allocation of social empathy; i.e., the share of $i$ 's social empathy allocated to the type $s$ agents corresponds precisely to the proportion of type $s$ agents in the population. Because of this feature and the conformity of behaviour, we call this type of $S E$ equilibrium cohesive.

The second type of equilibrium consists of corner solutions of the dynamic process of socioeconomic interactions. In such an equilibrium the population is partitioned into two groups or clusters, one set of individuals (type $s$ ) work above the mean and another set (type $u$ ) work below. The former have maximum self-esteem (and minimum empathy for others), while the latter have minimum self-esteem (and maximum social empathy). In addition the social empathy of every individual will be biased in favor of the industrious. Sentiments become endogenously polarized: those working below the average will be regarded as lazy - even by themselves - and suffer from both low social consideration and low self-esteem. We call such an $S E$ equilibrium clustered.

We now characterize the conditions under which either of the two types of $S E$ equilibria exist.

For given $\boldsymbol{\beta}$ and $\tau$, a cohesive $S E$ equilibrium consists of a vector $\varphi$ such that it is optimal for both types to supply the same quantity of labour $L$. Notice that $\varphi_{i}$ is constrained to belong to the interval $[\varphi, \bar{\varphi}]$. We start by noting that when $L_{i}=L$ for all $i$, the per capita transfer is given by $T=\tau \beta L .^{25}$ Using (18), we can identify the pairs of $\varphi_{i}$ and $\beta_{i}$ for which both types would choose to supply $L$. This is given implicitly as the solution to ${ }^{26}$

$$
F\left(\beta_{i}, \varphi_{i}, \beta, L, \tau\right) \equiv \lambda\left((1-\tau) \beta_{i}, \varphi_{i}, \tau \beta L\right)-L=0, \text { for } i=u, s .
$$

\footnotetext{
${ }^{25}$ Recall $\beta$ is the average productivity.

${ }^{26}$ Note that while the following expression contains the consistency requirement $T=\tau \beta L$, the first order condition (17), from which $\lambda$ is obtained, precludes consideration of the effect of one's labour supply on aggregate transfers. Therefore, the following expression should be viewed as an accounting relationship that is required to hold at an $S E$ equilibrium rather than as a first order condition.
} 
Next, we investigate values of $\beta$ and $\tau$ such that there exist $L$ and $\varphi_{i} \in[\varphi, \bar{\varphi}]$ for which (23) is satisfied for both $i=u, s$.

From (22) we know that for each $i$, there is a maximum labour supply, denoted by $\bar{L}_{i}\left(\tau, \beta_{i}, \beta\right)$, and a minimum labour supply $\underline{L}_{i}\left(\tau, \beta_{i}, \beta\right)$ that are compatible with $\varphi_{i}$ being in $[\underline{\varphi}, \bar{\varphi}]$. These are given implicitly by

$$
\underline{L}_{i}=\lambda\left((1-\tau) \beta_{i}, \bar{\varphi}, \tau \beta \underline{L}_{i}\right) \text { and } \bar{L}_{i}=\lambda\left((1-\tau) \beta_{i}, \underline{\varphi}, \tau \beta \bar{L}_{i}\right) .
$$

The next proposition establishes that a necessary and sufficient condition for the existence of a cohesive $S E$ equilibrium is that the intervals $\left[\underline{L}_{u}, \bar{L}_{u}\right]$ and $\left[\underline{L}_{s}, \bar{L}_{s}\right]$ have a non-empty intersection. Conversely, that the intersection is empty is both necessary and sufficient for there to exist a clustered $S E$ equilibrium.

Proposition 1. For any $(\boldsymbol{\beta}, \tau)$ the following hold:

i) A cohesive $S E$ equilibrium exists if and only if

$$
\bar{L}_{u}\left(\tau, \beta_{u}, \beta\right) \geq \underline{L}_{s}\left(\tau, \beta_{s}, \beta\right) .
$$

In this case there are generally multiple equilibria. That is, for every $L^{o} \in\left[\underline{L}_{s}\left(\tau, \beta_{s}, \beta\right), \bar{L}_{u}\left(\tau, \beta_{u}, \beta\right)\right]$ there exist $\varphi_{u}, \varphi_{s} \in[\underline{\varphi}, \bar{\varphi}]$ for which (23) is satisfied at $L_{i}=L^{o}$, for $i=u, s$. In all such equilibria $\alpha_{i, j}=\alpha_{i}$ for $i, j=u, s$.

ii) A clustered $S E$ equilibrium exists if and only if

$$
\bar{L}_{u}\left(\tau, \beta_{u}, \beta\right)<\underline{L}_{s}\left(\tau, \beta_{s}, \beta\right) .
$$

In this case, the equilibrium is unique and is given by:

$$
L_{u}=\lambda\left((1-\tau) \beta_{u}, \underline{\varphi}, T\right)<L_{s}=\lambda\left((1-\tau) \beta_{s}, \bar{\varphi}, T\right)
$$

where $\left.T=\tau\left((1-\pi) \beta_{u} L_{u}+\pi \beta_{s} L_{s}\right)\right)$, and by $\varphi_{u}=\underline{\varphi}, \varphi_{s}=\bar{\varphi}, \alpha_{i}=g^{-1}\left(\varphi_{i}\right)$, and $\alpha_{i, j}=\frac{L_{j}}{L} \alpha_{i}$ for $i, j=u, s$.

This proposition establishes that one or the other, but not both, of the two types of SE equilibrium will always exist. For any $\boldsymbol{\beta}$ it may be possible to observe multiple cohesive equilibria parametrized by the degree of industriousness and sustained by different degree of moral pressure to work while when it exists the clustered equilibrium is unique. Whether the equilibria are cohesive or clustered depends crucially on both the degree of inequality in $\boldsymbol{\beta}$ and the level of redistribution $\tau$. If inequality in $\boldsymbol{\beta}$ is too large, then the moderating effect of self-esteem on labour supply will be insufficient to overcome the difference, and cohesiveness will not be sustainable. On the other hand, redistribution equalizes the economic rewards to labour for the two types of workers and hence changes the relative return of moral and economic rewards to effort. These issues are investigated in greater detail in the next section where we consider the endogenous choice of redistributive policy.

Before turning to this, however, we highlight the relative differences of the two types of agents in any stationary equilibrium. In a clustered $S E$ equilibrium the unskilled are poorer and less industrious than the skilled despite having lower self-esteem and thus larger moral motivation to work. Also in any cohesive $S E$ equilibrium in which (23) is satisfied by both types for the same $L$, totally differentiating this expression with respect to $\beta_{i}$ and $\varphi_{i}$ and using (20) and (22), we readily obtain that

$$
\frac{\partial \varphi_{i}}{\partial \beta_{i}}>0
$$

Hence, in a cohesive equilibrium where all individuals work the same it must be that those who receive higher (lower) economic rewards feel less (more) moral pressure to work. Therefore, bearing in mind that altruism $\alpha_{i}$ is inversely related to self-esteem, we have the following result. 
Proposition 2. In any stationary SE equilibrium the individuals with higher productivity have greater self-esteem, lower altruism, and face lower moral motivation to work than those with low productivity.

\section{Endogenous Redistribution}

So far we have taken $\tau$ as given, and we have seen that attitudes and behaviour will differ depending upon the type of socioeconomic equilibrium to emerge. We begin this section by considering the opposite: what level of redistribution will be chosen by a group of individuals with given sentiments? We then categorize the effect of taxes in determining the type of $S E$ equilibrium.

\subsection{From Sentiments to Taxes}

On the majoritarian choice of income tax schedules we follow the approach developed by Romer (1975), Roberts (1977) and Meltzer and Richard (1981). In our case, the majority is constituted by unskilled workers and hence we shall focus on their preferences over taxes. Given their sentiments, individuals vote over redistribution. When voting, agents are aware of the distortions caused by income taxation on labour supply and anticipate the existence of a public budget constraint. ${ }^{27}$ Therefore, from equation (18), for given $\varphi_{i}$, the optimal labour supply is a function of the tax rate $\tau$ and of the per capita transfers $T: L_{i}(\boldsymbol{\beta}, \boldsymbol{\varphi}, \tau, T)$ for $i=u, s$. Notice, however, that the existence of the public budget allows to express the per capita transfer as a function of the tax rate. From (18) and (2) we have that

$$
T=\tau\left[(1-\pi) y_{u}(\tau, T)+\pi y_{s}(\tau, T)\right] \equiv \tau y(\tau, T)
$$

As in MR, for any $\tau$ the assumed normality of leisure insures that the RHS (right hand side) of (27) is a strictly decreasing function of $T$ implying that for any $\tau$ there exists a unique $T$ which balances the public budget. This allows us to express the per capita transfer and the individual indirect private utility as a function of $\tau$ only,

$$
\nu_{i}(\tau) \equiv v_{i}\left((1-\tau) y_{i}(\tau)+\tau y(\tau), \bar{L}-L_{i}(\boldsymbol{\beta}, \boldsymbol{\varphi}, \tau)\right),
$$

where $y_{i}(\tau) \equiv \beta_{i} L_{i}(\boldsymbol{\beta}, \boldsymbol{\varphi}, \tau)$ and $y(\tau) \equiv\left[(1-\pi) y_{u}(\tau)+\pi y_{s}(\tau)\right]$.

The degree of redistribution preferred by an unskilled worker, denoted $\tau^{u}$, maximizes its indirect total utility (9) subject to the public budget constraint (2), taking into account the induced change in the optimal labour supplies. Therefore, $\tau^{u}$ is the solution to the following maximization problem:

$$
\tau^{u}=\arg \max _{\tau \in[0,1]} V_{u}(\boldsymbol{\beta}, \boldsymbol{\varphi}, \tau)=\arg \max _{\tau \in[0,1]}\left\{\nu_{u}(\tau)+\alpha_{u}\left[\left(1-\sigma_{u}\right) \nu_{u}(\tau)+\sigma_{s} \nu_{s}(\tau)\right]\right\} .
$$

Consider, first, the preferred level of redistribution of an egoistic agent. With no social empathy, i.e. $\alpha_{u}=0$, the problem is identical to that in Meltzer and Richard (1981). Its solution, as given by the following first order condition, would constitute the majoritarian choice since the unskilled comprise a majority of the population: ${ }^{28}$

$$
\frac{d \nu_{u}(\tau)}{d \tau}=\frac{\partial v_{u}}{\partial c}\left[y-y_{u}+\tau \frac{d y}{d \tau}+(1-\tau) \beta_{u} \frac{\partial L_{u}}{\partial \tau}\right]+\frac{\partial v_{u}}{\partial L_{u}} \frac{\partial L_{u}}{\partial \tau}=0
$$

\footnotetext{
${ }^{27}$ In contrast, Kranich (2001) assumes that altruistic agents vote over quadratic taxes and modify their labour supply iteratively rather than simultaneously.

${ }^{28}$ In the remainder of the section we use the abbreviated notation $L_{i}$ for $L_{i}(\boldsymbol{\beta}, \boldsymbol{\varphi}, \tau), y_{i}$ for $y_{i}(\tau)$ and $y$ for $y(\tau)$ when no ambiguity will result.
} 
Using (17), this condition simplifies to

$$
\frac{d \nu_{u}}{d \tau}=\frac{\partial v_{u}}{\partial c}\left[y-y_{u}+\tau \frac{d y}{d \tau}\right]=0
$$

Therefore, the preferred tax rate is increasing in inequality (i.e., $y-y_{u}$ ). Let us denote by $\tau^{m}$ the tax rate satisfying the first order condition for an interior optimum in the egoistic case (29).

When $\alpha_{u}>0$, however, preferences over redistribution will be affected by both the degree of social empathy $\alpha_{u}$ and by the bias in the allocation of this empathy. The marginal effect on total utility of a variation in $\tau$ is given by

$$
\begin{aligned}
\frac{d V_{u}(\tau)}{d \tau}= & \frac{\partial v_{u}}{\partial c}\left[y-y_{u}+\tau \frac{d y}{d \tau}\right]+ \\
& +\alpha_{u}\left\{\left(1-\sigma_{u}\right) \frac{\partial v_{u}}{\partial c}\left[y-y_{u}+\tau \frac{d y}{d \tau}\right]+\sigma_{u} \frac{\partial v_{s}}{\partial c}\left[y-y_{s}+\tau \frac{d y}{d \tau}\right]\right\} .
\end{aligned}
$$

Notice that

$$
\left.\frac{d V_{u}(\tau)}{d \tau}\right|_{\tau=\tau^{m}}<0
$$

and this implies that when unskilled workers are socially concerned, they will prefer a tax rate smaller than $\tau^{m}$. Intuitively, if the poor are altruistic, then they are adversely affected by the rich having to bear the cost of redistribution. An interior solution for the equilibrium tax rate $\tau^{u}>0$ is characterized by setting (30) equal to zero and verifying that the indirect utility is locally concave at $\tau=\tau^{u}$

$$
\left.\frac{d^{2} V_{u}(\tau)}{d \tau^{2}}\right|_{\tau=\tau^{u}}<0
$$

These considerations imply the following,

Proposition 3. If $\alpha_{u}>0$, then for any given allocation of social empathy across groups $\boldsymbol{\sigma}$, and any $(\boldsymbol{\varphi}, \boldsymbol{\beta})$ such that $y_{u}<y$, we have that $\tau^{u}<\tau^{m}$. That is, the majority rule tax rate is smaller than in the egoistic case. Furthermore for any interior $\tau^{u}$ the equilibrium tax is decreasing in $\alpha_{u} \cdot{ }^{29}$

\subsection{From Taxes to Sentiments}

Given current sentiments $(\boldsymbol{\varphi}, \boldsymbol{\alpha})$, individuals vote over the tax policy as described in the previous subsection. But then the new tax policy might induce a change in behaviour, and this, in turn, might affect agents' self-esteem and relative empathy for others. In this subsection we begin to investigate the effect of $\tau$ on the type of stationary sentiments to emerge in equilibrium.

From Proposition 1 we know that for any given level of $\tau$ a cohesive equilibrium will emerge only if the unskilled face sufficient moral pressure to work (stemming from low self-esteem) to overcome the adverse incentive effect of taxation. Indeed, if $\tau$ is too large, this may reduce the return to labour to such an extent that moral suasion is insufficient even when self-esteem is minimal.

The intuition behind this result hinges on the normality of leisure which implies that, ceteris paribus, the incentive to supply labour diminishes as fiscal transfers become larger and the tax rate higher. In fact for any given vector $\varphi$, the negative effect of taxation on labour supply is

\footnotetext{
${ }^{29}$ Notice also that the level of redistribution preferred by the skilled is always lower than that preferred by the unskilled but it is (weakly) larger than the egoistic benchmark and it is (weakly) increasing in $\alpha_{s}$. Hence while the rich oppose any taxation in the egoistic benchmark, they may support redistribution in this setting. A formal proof is provided in the appendix.
} 
stronger for unskilled workers. The logic of the argument is as follows. Consider again (23), which identifies the quantities of labour compatible with a cohesive equilibrium: $F\left(\beta_{i}, \varphi_{i}, \beta, L, \tau\right) \equiv$ $\lambda\left((1-\tau) \beta_{i}, \varphi_{i}, \tau \beta L\right)-L=0$ for $i=u, s$. An increase in $\tau$ has two effects. In the first place it reduces the net wage of both types leading to a lower labour supply. In the second place because of the change in the lump-sum transfer, for any given cohesive labour supply $L$, the consumption of the unskilled increases. In fact in a cohesive equilibrium the consumption of agent $i$ is given by $c_{i}=\left[(1-\tau) \beta_{i}+\tau \beta\right] L=\left[\beta_{i}+\tau\left(\beta-\beta_{i}\right)\right] L$. Hence, an individual would consume more than its pre-tax earnings if and only if its productivity is below the mean. The $M R S$ between consumption and leisure increases and hence labour supply is reduced. For the unskilled workers, the two effects go in the same direction and this implies that the labour supply by the unskilled definitively decreases. For any $\beta L$, consumption decreases with $\tau$ for the skilled workers and this tends to increase labour supply. The two effects go in opposite directions so that the net result is ambiguous.

This differential effect of redistribution on the labour supply of the different types of agents implies that if redistribution is too large, then the economic incentives to the unskilled may be too weak. Under these conditions the moral incentives are insufficient to sustain a cohesive equilibrium.

At this level of generality it is not possible to explicitly characterize the link between redistribution and social cohesion. In order to further investigate the relationship between taxation and sentiments, we now restrict attention to the family of preferences given by

$$
v(c, l, \varphi)=\frac{c^{1-\theta}}{1-\theta}+\varphi f(\bar{L}-L)
$$

with $\theta \geq 0, f^{\prime}()>$.0 and $f^{\prime \prime}() \leq$.0 .

As we shall see, the effect of redistribution on sentiments will critically depend on the relative productivity of the two types of workers, which we denote by $\widetilde{\beta} \equiv \beta_{u} / \beta_{s} \in[0,1]$. In line with the previous discussion on the differential role of redistribution on moral and economic incentives we have the following,

Proposition 4. For any $\widetilde{\beta}$, there exists a unique threshold level of redistribution $\tau(\widetilde{\beta}) \in[0,1]$ such that for any $\tau \leq \tau(\widetilde{\beta})$ only cohesive SE equilibria exist, while for any $\tau>\tau(\widetilde{\beta})$ only clustered SE equilibria exist. ${ }^{30}$ Furthermore the larger the gap in productivities the lower the level of maximum redistribution: $\partial \tau(\widetilde{\beta}) / \partial \widetilde{\beta}>0$.

According to this proposition, the choice of $\tau$ will lead to a cohesive (clustered) equilibrium if $\tau$ is sufficiently small (large). Moreover, the critical level, $\tau(\widetilde{\beta})$, depends on the productivity ratio. If $\widetilde{\beta}$ is sufficiently large or sufficiently small, then the choice of $\tau$ will have no influence on the type of equilibrium. In the former case, the difference in wages is small enough so that the economy always settles in a cohesive equilibrium, while in the latter, it settles in a clustered equilibrium. We state this result in the following.

Proposition 5. There exist two thresholds of relative skills, $\widetilde{\beta}_{0}$ and $\widetilde{\beta}_{1}, 0 \leq \widetilde{\beta}_{0} \leq \widetilde{\beta}_{1}<1$, such that for any given $\tau$ there is $\bar{\beta}(\tau) \in\left[\widetilde{\beta}_{0}, \widetilde{\beta}_{1}\right]$ such that for any $\widetilde{\beta}>\bar{\beta}(\tau)$ only cohesive $S E$ equilibria exists while for any $\widetilde{\beta}<\bar{\beta}(\tau)$ only clustered $S E$ equilibria exist with $\partial \bar{\beta}(\tau) / \partial \tau>0$.

If $\widetilde{\beta}$ is outside the thresholds the type of equilibrium does not depend on the tax rate. For intermediate levels of inequality the type of equilibrium crucially depends on redistribution: low taxation produces cohesive equilibria and high taxation clustered equilibria.

\footnotetext{
${ }^{30}$ As discussed in detail below, $\bar{\tau}(\widetilde{\beta})$ is not necessarily interior. Therefore, under some circumstances it may be the case that only cohesive or only clustered equilibria can be observed for all $\tau \in[0,1]$.
} 


\section{Politico-Economic Equilibria}

In the last section we studied how sentiments affect the choice of taxes and how the level of redistribution leads to different equilibrium sentiments. We now focus on the full politicoeconomic equilibrium of the model (henceforth $P E$ equilibrium) in which sentiments, labour supplies and taxes are each variable and all are required to be mutually compatible. Thus, a $P E$ equilibrium is characterized by a vector $(\mathbf{L}, \boldsymbol{\varphi}, \boldsymbol{\alpha}, \tau)$ such that $(\mathbf{L}, \boldsymbol{\varphi}, \boldsymbol{\alpha})$ is an $S E$ equilibrium at the tax rate $\tau$, and $\tau$ solves (28).

\subsection{Existence and Uniqueness}

In order to study the implications of social cohesion more precisely, we now characterize the equilibria for a restricted class of economies which permit an explicit analytical solution. Specifically, we consider the following specific forms of (32) and $(14)^{31}$

$$
v\left(c_{i}, L_{i}, \varphi_{i}\right)=c_{i}+\left(1-\frac{L_{i}^{2}}{2}\right) \varphi_{i}
$$

and

$$
\varphi_{i}=\frac{1}{1+\alpha_{i}} .
$$

In this case, the labour supply is given by,

$$
L_{i}\left(\beta_{i}, \varphi_{i}, \tau\right)=(1-\tau) \beta_{i} \frac{1}{\varphi_{i}}=(1-\tau) \beta_{i}\left(1+\alpha_{i}\right) .
$$

As an index of inequality, we use the relative gap between mean and median income,

$$
I \equiv \frac{y-y_{u}}{y} .
$$

Notice that in this case $I$ is proportional to the Gini index, which is given by $G=(1-\pi) I$.

We now define $\widetilde{y}^{u}$ as the moral perception of mean income by the unskilled:

$$
\widetilde{y}_{u} \equiv\left[\left(1-\sigma_{u}\right) y_{u}+\sigma_{u} y_{s}\right]
$$

According to $\widetilde{y}_{u}$, the unskilled weight the two incomes by the moral weights $\sigma_{u}$ and $\left(1-\sigma_{u}\right)$ rather than by the population weights $\pi$ and $(1-\pi)$. This reflects the fact that the former may be biased in assigning greater weight to one group than their population proportion warrants. We take a measure of such bias to be

$$
\delta \equiv \frac{\left(y-\widetilde{y}_{u}\right)}{y} .
$$

Hence, $\delta$ is the relative difference between the true mean and the moral perception of mean income. Notice that in a cohesive equilibrium $\sigma_{u}=\pi$, and hence $\delta=0$. In a clustered equilibrium $u$ 's empathy is biased in favor of high productivity individuals, so $\sigma_{u}>\pi$ and we have $y<\widetilde{y}_{u}$ and hence $\delta<0$. Here, because of the linearity of the labour supply functions (35) we have ${ }^{32}$

$$
\delta=-\pi(1-\pi) \frac{1-2 \widetilde{\beta}}{\pi+(1-\pi) 2 \widetilde{\beta}} \frac{1-2 \widetilde{\beta}^{2}}{\pi+(1-\pi) 2 \widetilde{\beta}^{2}} .
$$

\footnotetext{
${ }^{31}$ The linear-quadratic formulation of utility has often been adopted in the literature. See, for example, Piketty (1995) and Alesina and Angeletos (2005)).

${ }^{32}$ From the definition we have

$$
\delta=\frac{\left(\sigma_{u}-\pi\right)\left(2 \beta_{u}^{2}-\beta_{s}^{2}\right)}{(1-\pi) 2 \beta_{u}^{2}+\pi \beta_{s}^{2}}
$$

where $\sigma_{u}=\pi \beta_{s} /\left[(1-\pi) 2 \beta_{u}+\pi \beta_{s}\right]$. Substituting and manipulating, we obtain the expression in the text.
} 
It follows that in a clustered $P E$ equilibrium the bias $\delta$ depends on exogenous parameters only and is independent of $\tau$.

The indirect private utility of an individual of type $i$ is given by

$$
v\left(\tau, T, \beta_{i}, \varphi_{i}\right)=\frac{(1-\tau)^{2} \beta_{i}^{2}}{2 \varphi_{i}}+T(\tau)+\varphi_{i} .
$$

Using (35), we obtain the following expressions for the effects of $\tau$ on labour, gross earnings and transfers, respectively:

$$
\frac{d L_{i}}{d \tau}=-\frac{L_{i}}{1-\tau}, \frac{d y_{i}}{d \tau}=-\frac{y_{i}}{1-\tau} \text { and } \frac{d T}{d \tau}=\frac{1-2 \tau}{1-\tau} y
$$

Differentiating the egoistic (indirect) utility $v_{i}(40)$ with respect to $\tau$, we obtain

$$
\frac{d v_{i}}{d \tau}=y-y_{i}-\frac{\tau}{1-\tau} y
$$

Then differentiating the total indirect utility (9) with respect to $\tau$, we get the first order condition

$$
\frac{d V_{u}}{d \tau}=\left(1+\alpha_{u}\right) \frac{1-2 \tau}{1-\tau} y-y_{u}-\alpha_{u} \widetilde{y}^{u}=0 .
$$

Let us assume for the moment that the first order condition for redistribution identifies a maximum. Solving (43) and using the definitions of $I$ and $\delta$, we obtain the unique preferred tax by an unskilled individual,

$$
\tau^{u}=\frac{I+\alpha_{u} \delta}{1+\alpha_{u}+I+\alpha_{u} \delta} .
$$

Let us now turn to the conditions for an interior optimum. Using the labour supply functions (35) in (9), one can show that the indirect total utility is a quadratic function of $\tau{ }^{33}$ Furthermore $V_{u}(0)>V_{u}(1)$. Therefore, $\partial V_{u}(0) / \partial \tau>0$ is necessary and sufficient for the existence of a unique interior optimum. In the following proposition we identify the condition under which this inequality holds.

Proposition 6. For any $(\boldsymbol{\alpha}, \boldsymbol{\beta}, \pi)$ the tax rate $\tau^{u}$ preferred by an unskilled individual is given $b y^{34}$

$$
\tau^{u}=\frac{I+\alpha_{u} \delta}{1+\alpha_{u}+I+\alpha_{u} \delta}, \text { if } \pi>\frac{\alpha_{u}}{1+\alpha_{u}} \sigma_{u},
$$

and $\tau^{u}=0$ otherwise.

${ }^{33} \mathrm{Using}(35)$ we can express the indirect utility of individual $i$ as

$$
\begin{aligned}
V_{i}(\tau)= & \varphi_{i}+\alpha_{i}\left[\left(1-\sigma_{u}\right) \varphi_{u}+\sigma_{u} \varphi_{s}\right]+\frac{(1-\tau)^{2}}{2}\left\{\beta_{i}^{2} \frac{1}{\varphi_{i}}+\alpha_{i}\left[\left(1-\sigma_{u}\right) \beta_{u}^{2} \frac{1}{\varphi_{u}}+\sigma_{u} \beta_{s}^{2} \frac{1}{\varphi_{s}}\right]\right\} \\
& +(1-\tau) \tau\left(1+\alpha_{i}\right)\left[(1-\pi) \beta_{u}^{2} \frac{1}{\varphi_{u}}+\pi \beta_{s}^{2} \frac{1}{\varphi_{s}}\right] .
\end{aligned}
$$

${ }^{34}$ Differentiating and evaluating at $\tau=0$, we have the condition

$$
V_{u}^{\prime}(0)=\left(\frac{\beta_{s}^{2}}{\varphi_{s}}-\frac{\beta_{u}^{2}}{\varphi_{u}}\right)\left(\alpha_{u}\left(\pi-\sigma_{u}\right)+\pi\right)
$$

Using the labour supply functions (35), we have that $\left(\frac{\beta_{s}^{2}}{\varphi_{s}}-\frac{\beta_{u}^{2}}{\varphi_{u}}\right)>0$ in any stationary equilibrium. 
Inspection of (44) reveals that, ceteris paribus, the chosen tax is increasing in $I$ and in $\delta$. As mentioned earlier, if $\alpha_{u}=0$, then the problem becomes identical to MR and the demand for redistribution is increasing with inequality $I$. Relative to this benchmark, when $\alpha_{u}>0$ preferences over redistribution will be affected by the degree of social empathy and by the bias in the allocation of this empathy as captured by $\delta$. Poor altruistic individuals will weigh the cost of taxation to the rich against the benefits of redistribution towards the poor. As a result, as in Proposition 2, their redistributive demands may be more moderate than under pure egoism. As for the role of the bias in individual sentiments, the direction in which $\tau^{u}$ diverges from the benchmark case is determined by the sign of $\delta$, i.e. it depends on whether the unskilled have a pro-poor or pro-rich bias.

We now characterize the $P E$ equilibria. We begin by restating the conditions of Proposition 5 . Due to the linearity of the labour supply function (35) the thresholds $\widetilde{\beta}_{0}$ and $\widetilde{\beta}_{1}$ coincide. To see this, note that according to (35), the extreme values of $\bar{L}_{u}(\boldsymbol{\beta})$ and $\underline{L}_{s}(\boldsymbol{\beta})$ are

$$
\begin{aligned}
\bar{L}_{u}(\boldsymbol{\beta}) & =2(1-\tau) \beta_{u} \\
\underline{L}_{s}(\boldsymbol{\beta}) & =(1-\tau) \beta_{s} .
\end{aligned}
$$

Hence, an economy is in a cohesive $P E$ equilibrium, i.e., $\bar{L}_{u}(\boldsymbol{\beta}) \geq \underline{L}_{s}(\boldsymbol{\beta})$, if and only if

$$
\beta_{s} \leq \frac{L}{(1-\tau)} \leq 2 \beta_{u}
$$

Expression (45) gives the pairs $(\tau, L)$ that are consistent with a cohesive $P E$ equilibrium. From Proposition 5 and using (45) we have that the economy will be in a cohesive (respectively clustered) equilibrium if and only if

$$
\widetilde{\beta} \geq(<) \frac{1}{2} .
$$

The implication of this is that, given $\widetilde{\beta}$, the economy will be in either type of equilibrium independently of the $\operatorname{tax} \tau$. Therefore, we can examine the characterization of the politicoeconomic equilibrium separately in the two ranges $\widetilde{\beta} \gtrless 1 / 2$.

Also because of the linearity of the labour supply function (35), $I$ is independent of $\tau$. Substituting into (36), we obtain

$$
I^{*}=\frac{\pi(1-\widetilde{\beta})}{\pi+(1-\pi) \widetilde{\beta}} \text { if } \widetilde{\beta} \geq \frac{1}{2} \text { and } I^{o}=\frac{\pi\left(1-2 \widetilde{\beta}^{2}\right)}{\pi+(1-\pi) 2 \widetilde{\beta}^{2}} \text { if } \widetilde{\beta}<\frac{1}{2} .
$$

Therefore, in spite of the potential multiplicity of cohesive $P E$ equilibria, all will be characterized by the same degree of income inequality, which depends only on the exogenous parameters $\widetilde{\beta}$ and $\pi$.

In order to compare income inequality across the two types of equilibria, consider economy $A$ with $\widetilde{\beta}_{A}$ which is clustered $\left(\widetilde{\beta}_{A}<\frac{1}{2}\right)$ and economy $B$ with $\widetilde{\beta}_{B}$ which is cohesive $\left(\widetilde{\beta}_{B} \geq \frac{1}{2}\right)$. Observe that $I^{o}$ in (47) is strictly decreasing in $\widetilde{\beta}$. Also, note that $\widetilde{\beta}_{A}<1 / 2<\widetilde{\beta}_{B}$ implies $2 \widetilde{\beta}_{A}^{2}<1 / 2<\widetilde{\beta}_{B}$. Finally, we also have that

$$
I^{*}(1 / 2)=I^{o}(1 / 2)=\bar{I} \equiv \frac{\pi}{1+\pi} .
$$

Taken together, these observations establish the following:

Lemma 1. The degree of income inequality in a clustered (cohesive) economy is always larger (smaller) than $\bar{I}$. 
Next, we characterize the features of both cohesive and clustered equilibria. We begin with the former.

As established above, a cohesive equilibrium can exist only if the ratio $\frac{L}{(1-\tau)}$ lies within the fixed bounds given by (45). However, there is nothing to preclude the preferred tax, $\tau^{u}$, from violating this condition for each $L$. Consider any distribution of social concerns compatible with a cohesive equilibrium. Since all groups contribute to total labour supply in proportion of their size, individual esteem is unbiased and $\delta=0$. Substituting into (44), the preferred tax is:

$$
\tau^{*}=\frac{I^{*}}{1+\alpha_{u}+I^{*}} .
$$

The values of $\alpha_{u}$ are bounded above by 1 and below by $\hat{\alpha}_{u}(I)$ corresponding to the minimum level of altruism by the unskilled workers compatible with any cohesive equilibrium (this corresponds to the case in which the skilled workers are fully egoistic). From (35) and (45) we find that

$$
\hat{\alpha}_{u}(I) \equiv \frac{1-\widetilde{\beta}}{\widetilde{\beta}}=\frac{I^{*}}{\left(1-I^{*}\right) \pi} .
$$

As shown in Proposition 3, redistribution is decreasing with $\alpha_{u}$, while labour supply is increasing in $\alpha_{u}$. As a result there can be a continuum of values of $\alpha_{u}$ for which a cohesive $P E$ equilibrium exist. Therefore, we obtain the following:

Proposition 7. For any $(\boldsymbol{\beta}, \pi)$ such that $I \leq \bar{I}$, every cohesive SE equilibrium with a tax rate

$$
\tau^{*} \in\left[\frac{I^{*}}{2+I^{*}}, \frac{I^{*}}{K^{*}+I^{*}}\right]
$$

where $K^{*} \equiv \frac{I^{*}+\pi\left(1-I^{*}\right)}{\pi\left(1-I^{*}\right)}<2$, is a PE equilibrium.

The intuition for this result is as follows. Different equilibria differ in the level of equilibrium effort and in the degree of redistribution. We depict the combinations of $L$ and $\tau$ compatible with the bounds (45) in Figure 1.

Figure 1 About Here

Notice that the area between lines $L_{u}$ and $L_{s}$ represents cohesive $S E$ equilibria for any given value of $\tau$. Alternatively, the locus $T T$ contains the vectors $(\tau, L)$ for which individual labour supply and the chosen level of redistribution are mutually compatible. ${ }^{35}$ Therefore, the cohesive $P E$ equilibria correspond to the intersection of the $T T$ locus with the set of cohesive $S E$ equilibria. The maximum labour supply and minimum $\tau^{u}$ are associated with $\alpha_{u}=1$, while minimum labour supply and maximum $\tau^{u}$ are associated with $\hat{\alpha}_{u}(I)$. It is immediate that in any cohesive $P E$ equilibrium the higher the tax, the lower is the labour supply and output.

Notice that the multiplicity of cohesive equilibria (i.e., the size of the intersection) shrinks as $I$ gets larger, and in the limit, where $I^{*}=\bar{I}$, the cohesive equilibrium is unique since $\lim _{I \rightarrow \bar{I}} \hat{\alpha}_{u}(I)=1$.

Turning now to clustered equilibria, we know from Proposition 5, (47) and (39), that for such equilibria income inequality is $I^{o}>\bar{I}$, and, moreover, that both $I^{o}$ and the bias $\delta^{o}$ are independent of the tax rate. Therefore, given $\widetilde{\beta}$ and $\pi$, there will be a unique level of $\tau$ in a $P E$ equilibrium.

\footnotetext{
${ }^{35}$ The analytical computation of the locus $T T$ is included in the Appendix.
} 
Proposition 8. For any $(\boldsymbol{\beta}, \pi)$ such that $I^{o} \geq \bar{I}$, there exists a threshold $I_{c} \in(\bar{I}, 1)$ such that the unique clustered PE equilibrium tax is given by

$$
\tau^{o}=\left\{\frac{I^{o}+\delta^{o}}{2+I^{o}+\delta^{o}} \quad \text { if } \quad I \in\left[\bar{I}, I_{c}\right),\right.
$$

where $I^{o}$ is given in (47) and $\delta^{o}$ in (39), while $\tau^{o}=0$ if $I \in\left(I_{c}, 1\right]$.

That there is such a threshold above which $\tau^{o}=0$ derives from the condition for a corner solution for $\tau^{u}$, as stated in Proposition 6. For clustered equilibria, this condition can be rewritten as $\sigma_{u} \geq 2 \pi$, which at the equilibrium value of $\sigma_{u}$ (from (10)) is equivalent to $\widetilde{\beta} \leq$ $(1-2 \pi) / 4(1-\pi)$. Using this information, one can obtain the unique threshold level of $I_{c}$ from $(47)$.

\subsection{Inequality, Social Cohesion and Redistribution}

We now investigate the relationship between income inequality and equilibrium redistribution.

In the previous subsection we saw that for low levels of inequality there is generally a continuum of cohesive $P E$ equilibria corresponding to the range of $\tau^{*}$ in (51). But for all such equilibria, inequality is given by $I^{*}$ in (47), and $I^{*}$ depends only on the exogenous parameters $\pi$ and $\tilde{\beta}$. Notice also that the upper bound on $\tau^{*}$ depends on $\pi$ as well as on $I^{*}$.

For high levels of inequality the economy has a unique clustered $P E$ equilibrium, with the corresponding degree of inequality given by $I^{o}$ in (47). In this case, too, the clustered $P E$ equilibrium tax $\tau^{o}$ depends - via $\delta^{o}-$ on $\pi$ and $\tilde{\beta}$, as well as on $I^{o}$. In the following exercise, we hold $\pi$ constant and classify different economies/levels of inequality by variations in $\tilde{\beta}$.

As a preliminary result notice that while in cohesive equilibria $\delta=0$, in clustered equilibria the bias towards the more industrious workers, i.e. the degree of social clustering, is increasing with inequality. We state this formally in the following lemma.

Lemma 2. For $I \leq \bar{I}, \delta=0$, and for $I>\bar{I}, \delta<0$ with $\partial \delta / \partial I<0$.

This observation has important implications for the relationship between income inequality and equilibrium redistribution.

The following proposition establishes the relationship between inequality and equilibrium redistribution in both cohesive and clustered economies.

Proposition 9. (i) For any $I \leq \bar{I}$, both minimum and maximum redistribution among cohesive PE equilibria, $\tau_{m}^{*}=\frac{I^{*}}{2+I^{*}}$ and $\tau_{M}^{*}=\frac{I^{*}}{K^{*}+I^{*}}$, are increasing in inequality.

(ii) For any $I \geq \bar{I}$ the clustered $P E$ equilibrium $\tau^{o}$ is a nonmonotonic function of inequality: there exists a level of inequality $I^{s}>\bar{I}$ at which $\tau^{o}$ is maximal. Furthermore for any $I \geq I_{c}>\bar{I}$, $\tau^{o}=0$.

Figure 2 illustrates these findings.

Figure 2 About Here

The intuition behind this result is as follows. Consider first the case of a cohesive society. Individual utility combines an egoistic component and a social component. As in the standard non-altruistic utility benchmark, the egoistic component would lead to an increase in taxation in response to higher inequality. As for the social component, it would mimic the choice of taxation by a utilitarian social planner. Hence, when we take the two components together, an increase in inequality would unambiguously lead to an increase in taxation.

In clustered economies, the highly skilled individuals work above average and, as a result, social sentiments are biased in their favor. This bias tends to reduce the demand for taxation by 
the poor. The strength of the bias in social sentiments depends on the level of inequality. From Lemma 2, the higher the inequality, the stronger the bias towards the rich and the lower the demand for redistribution stemming from the social component of utility. In this case, the egoistic and the social component of the utility work in opposite directions. For values of inequality slightly above $\bar{I}$ the degree of social clustering and the associated bias in sentiments are small. ${ }^{36}$ Under these conditions an increase in inequality leads to an increase in redistribution. However, for a sufficiently high degree of inequality, the increase in social clustering and the associated bias eventually overtake the egoistic demand for greater taxation, and the tax preferred by the unskilled decreases. In fact there always exists a sufficiently high level of inequality such that $\tau^{o}=0$.

Summarizing, among cohesive economies, higher inequality is always associated with higher taxation. But as inequality increases beyond the threshold and the economy becomes clustered eventually the equilibrium tax rate declines. Hence, our model predicts a nonmonotonic relationship between inequality and redistribution. ${ }^{37}$

\section{Discussion}

We have developed a model in which individual labour supply, attitudes toward others as well as toward oneself, and the choice of taxation are determined endogenously. Given individual preferences for consumption and leisure, the degree of pre-tax (factor) income inequality is a key determinant of the type of equilibrium that prevails in a given economy. In a cohesive equilibrium all individuals conform to the ethical work norm and supply the same amount of labour with the moral pressure to work decreasing with the skill level. Furthermore, their concern for others is not biased toward either group. In this case, the level of taxation increases with inequality. But such an equilibrium can emerge only if pre-tax inequality is not too large. If inequality is high, the economy settles into an equilibrium with social clustering in which the more productive individuals work more than the less productive and no social norm emerges. In these equilibria the highly productive have maximum self-esteem and minimum relative esteem for others, while the low productivity types have minimum self-esteem and maximal esteem for the skilled workers. High inequality leads to a large bias in social concern thereby inducing the poor to choose low redistribution. In sum, the model brings into a common framework a rich set of seemingly unrelated predictions concerning behaviour in the labour market, moral attitudes and preferences for redistribution.

Next we discuss the predictions of the model in line with available cross-country evidence. To this effect, we shall use data from a set of OECD countries to illustrate how the predictions of the model concerning the two types of equilibria fit empirical evidence. We shall see that the information available is consistent with the hypothesis that the US - and less neatly the UK are more clustered societies than continental European countries such as Germany, France or the Netherlands. The contrast between the US and the EU economies has become an important topic of research. Most of the discussion has focused on the differences in the degree of redistribution - or more generally the differences in the two kinds of welfare states - and in the working of the labour market. To these we shall add differences in attitudes toward work and toward the poor.

Inequality and Redistribution. One of the most marked differences between the US and the (continental) EU is the extent of redistribution. The share of welfare transfers over

\footnotetext{
${ }^{36}$ In fact, as anticipated above, as long as social clustering is small enough, clustered and cohesive equilibria are similar in terms of equilibrium redistribution.

${ }^{37}$ Notice that for illustrative convenience we expressed the relationship between redistribution and the inequality index $I$. Since the Gini index is given by $G=(1-\pi) I$ the non monotonic relationship emerging in Proposition 9 holds also once expressed in terms of Gini coefficients as proved in the appendix.
} 
GDP in 2000 was 11 percent in the US and 18 percent in Europe, and the share of total government spending for the same year (excluding interest payments) was 30 percent and 45 percent, respectively. On this point, we refer the interested reader to the comprehensive analysis of Alesina and Glaeser (2004) and Alesina, Glaeser, and Sacerdote (2001). These differences in the extent of redistribution are coupled with significantly higher income inequality in the US than in EU countries. Concerning pre-tax earnings inequality, Katz and Autor (1999) report that the log of the ratio of the 90th percentile to the 10th percentile earner in 1994 was 1.45 in the US and 0.81 in Germany, for instance. Furthermore, several authors find that the dispersion in earnings and wages has increased over the $70 \mathrm{~s}$ to the $90 \mathrm{~s} .{ }^{38}$ This trend toward increased polarization in earnings and wages has led some sociologists and economists to argue that in the US the middle class is disappearing. ${ }^{39}$ The second dimension of inequality relevant to the model is the distribution of skills. Several authors, see e.g. Katz and Autor (1999) work of Devroye and Freeman (2001) addresses the problem of definition and measurement of skills using the OECD's International Adult Literacy Survey to assess the cognitive skills of the respondents. They document a much larger variation in the US, UK and Canada than in continental Europe. ${ }^{40}$ According to Acemoglu (2003), high school graduates in the US enjoy a skill premium that is about $50 \%$ larger than in Europe. According to Proposition 9, this negative relationship between pre-tax income inequality and the level of redistribution suggests that the US must be more clustered than the EU countries.

To investigate the relationship between inequality and redistribution in more details we use the data on factor income inequality provided by Milanovic (2000). The notion of factor income excludes all transfer payments from public sources, most notably pensions. This creates some difficulty when comparing societies with a strong system of public pensions such as in the EU with the US. Therefore, in order to make the comparison meaningful, we use the calculated measure of factor income inequality which includes pension transfers (referred to as factor- $P$ income). ${ }^{41}$

In order to interpret the data it is useful to note that for linear income taxes the (constant) marginal tax rate is equal to the ratio of the difference between the Ginis of the pre-tax and aftertax incomes over the Gini of the pre-tax income. Therefore, by relating the percentage variation and the level of factor income inequality, we can study the relationship between inequality and redistribution. Figure 3 plots the data for the percentage change in inequality from factor- $P$ income to disposable income and the Gini for the factor- $P$ incomes for a number of OECD countries. The percentage change in factor income provides a measure of income redistribution (and with linear progressive taxes is also a measure of the marginal tax rate $\tau$ ).

\section{Figure 3 About Here}

The least unequal countries are Luxemburg, Norway and Germany with Ginis around 0.36 and the associated tax rate ranging from 0.15 to 0.25. Next, we have Sweden and Belgium both with a Gini of 0.38 and the same tax rate of 0.31, followed by Finland and Denmark with higher inequality and redistribution. For higher degrees of inequality, countries redistribute less and less. For example, Canada and the Netherlands, with Ginis of 0.41, both tax at the rate 0.21. France with a Gini of 0.43 has a tax rate of 0.19 and the US has a Gini of 0.46 and taxes at

\footnotetext{
${ }^{38}$ See Katz and Autor (1999), Devroye and Freeman (2001) and Autor et al. (2006) among others.

${ }^{39}$ See, for instance, Kosters and Ross (1988) and Horrigan and Haugen (1988) and Duncan, Smeeding, and Rodgers (1991). Wolfson (1994) and Esteban and Ray (1994) mention this phenomenon as a motivation for the concept of "polarization" of a distribution.

${ }^{40}$ The mean and standard deviation (in brackets) are respectively: US 283 (60), UK 281 (53), Germany 291 (40) and the Netherlands 295 (40).

${ }^{41}$ The data correspond to the following years: Australia 1994, Belgium 1992, Canada 1994, Denmark 1992, Finland 1995, France 1989, West Germany 1989, Italy 1991, Luxemburg 1994, The Netherlands 1991, Norway 1991, Spain 1990, Sweden 1992, UK 1991, US 1991.
} 
the rate 0.14. In line with Proposition 9, the data display a nonmonotonic relationship between inequality and redistribution.

Inequality and the Labour Market. The second neat empirical implication of our model is that for low levels of inequality we should observe (little or) no dispersion in the distribution of labour supply, but after reaching the critical level for clustering to occur, further increases in inequality should be associated with increased dispersion in labour supply. In order to contrast this prediction with available evidence we again use the data on inequality in factor- $P$ income together with the information supplied by the OECD on working hours. ${ }^{42}$. By computing the fraction of the population at the mode of the distribution we have a simple indicator of the degree of compliance with the work norm, taken here to be the modal number of hours. ${ }^{43}$

Figure 4 About Here

In this case, the outlying country is Norway. If we focus on the rest, we observe that up to the degree of inequality 0.41 , the different countries are situated around 70 percent compliance with the work norm. This set of countries includes Luxembourg, Germany, Sweden, Belgium, Finland, Denmark and the Netherlands. France and Canada, with similar levels of inequality, have degrees of compliance of 55 and 42 percent, respectively. The US and Australia, with significantly more inequality, have compliance rates of 35 and 18 percent, respectively. Finally, the UK distribution has basically no mode. ${ }^{44}$

One could argue that it is to be expected that higher factor income inequality would be accompanied by higher dispersion in hours worked. However, it is remarkable that, in line with the theoretical predictions of our model, until inequality reaches a threshold level (around Gini $=0.41$ ) the degree of compliance shows basically no trend. It is after that point that additional inequality materializes in significant drops in the degree of compliance with the reference norm. Thus, using our model, we could infer that the first set of countries are cohesive while the second set are increasingly clustered.

A second possible reservation is that the labour market in continental Europe is heavily regulated and that this can explain the strong concentration around the regulated duration of the work week. However, as pointed out by Alesina, Glaeser and Sacerdote (2005) labour market regulations are most likely endogenous because unions tend to implement regulations in line with the preferences of the workers they represent. According to this argument, we should interpret these regulations as a coordination device rather than as a binding constraint on a significant part of the labour force. In this regard, the findings of Bell and Freeman (2001) on workers' preferences show that (continental) European workers would like to work less rather than more. In contrast, a larger fraction of US workers express preferences for working more even if their market is subject to fewer regulations. This suggests that the observed differences in the degrees of compliance result from different work norms rather than undesired labour market regulations. ${ }^{45}$

\footnotetext{
${ }^{42}$ Employment Outlook (Chapter 5, p. 168) based on the European Union labour Force Survey (Eurostat) and the Current Population Survey for the US on the distribution of the population by the number of working hours per week. We work with the data for the year 1994 to keep consistency with the years for which we have information on pre-tax inequality.

${ }^{43}$ In the case in which there is a minor peak adjacent to the mode we have grouped the two observations (for example for Germany there are two peaks: 38 and 40 hours).

${ }^{44}$ Using the data reported in Rubery et al. (1998), which report the full distribution of hours without aggregating those working more than 50 hours, we obtain a peak at 40 hours with $13 \%$ of workers. This is the data used in Figure 4 for the UK.

${ }^{45}$ Concerning the US labour market, Autor et al. (2006) document that wage inequality in the top half of the distribution has displayed a sustained and smooth secular rise for the last 25 years. Kuhn and Lozano (2005) point out that the polarization of labour supply increased overtime work and that in 2002, the best-paid 20 percent were twice as likely to work long hours as the bottom 20 percent. Also they find that this phenomenon cannot be attributed to decreased unionization.
} 
We have so far referred to the dispersion of work hours rather than to the average level of labour supply. In our model aggregate labour supply depends negatively on the tax rate, as would be expected. The direct effect of increased inequality, for any given tax rate, also has a negative effect. ${ }^{46}$ It follows that, for the range of inequality values for which the equilibrium tax increases in response to inequality, aggregate labour supply unambiguously decreases as inequality rises. However, as inequality enters the range where the chosen tax decreases there will be two opposing forces at work. In this range, the net effect will depend idiosyncratically on the magnitude of these opposing forces. But in principle, if inequality in the US is sufficiently high that it lies in the region of decreasing taxes, then it is consistent with the model that average labour supply in the US would exceed that in most EU countries, which is indeed the case. Recently, Prescott (2004) has pointed out that Americans actually work 50\% more than Germans, French and Italians and argues that most of the observed difference is explained by the different degree of income taxation. The understanding of the actual sources of these differences is an object of lively debate. ${ }^{47}$

Inequality and Individual Attitudes. The model delivers implications concerning individual moral attitudes toward work and toward the poor. Concerning individual attitudes, from Proposition 2 in any equilibrum of the model we shall observe a negative relationship between individual skill level and self-esteem. This is the case since in all equilibria the degree of moral-intrinsic motivation to work relative to economic incentives is decreasing with skill levels. Unfortunately data on self-perception or self-esteem in explicit relationship to work values are not available for the OECD countries we are considering. However, and with the due caution, it is possible to use directly the data on individual attitudes toward "work as a moral value" to test our novel prediction of a negative correlation between skill and moral pressure to work. ${ }^{48}$ Using survey data for eighteen OECD countries, we identify work motivation with the importance attached to "working hard" as captured by the degree of agreement with the statement, "Work is a duty towards society". ${ }^{49}$

According to our model, within each country work values should decrease with skill level, captured here by the level of educational attainment. Furthermore, this negative relation should be more pronounced for more unequal countries (with larger differences in earnings), possibly achieving a maximum for clustered economies. Indeed, the data display a significant and negative correlation between individual moral work motivation and skill level in most of the countries and for most of the variables concerning work. ${ }^{50}$ Figure 5 plots the relationship between factor- $P$

\footnotetext{
${ }^{46}$ The reason is that a reduction of the relative productivity of the unskilled workers - who are the most motivated - has a stronger negative effect on their labour supply than the positive effect for the less motivated, highly skilled workers. Therefore, a mean preserving spread in productivity/inequality tends to decrease labour supply for any given $\tau$.

${ }^{47}$ Rogerson (2005) investigates in detail this striking observation and also finds differential taxation to be key. Alesina, Glaeser and Sacerdote (2005) provide an extensive analysis of the different attitudes toward labour supply to explain the observation of large differences in the average work week. They argue that differential taxation cannot fully explain the observed differences and suggest that the existence of a social multiplier could explain the observation. Burda et. al. (2006) argue that the data may be explained by different social norms for leisure.

${ }^{48}$ We use survey data from the "Human Beliefs and Values: a cross-cultural sourcebook based on the 1999-2002 values surveys" edited by Inglehart et al. (2004) and the third wave of the survey concerning attitudes toward the poor (1994). The data consists of information about the respondent's income and education level as well as the degree of agreement with a series of statements (on a five-point Likert scale ranging from "strongly agree" to "strongly disagree").

${ }^{49}$ Apart from this question (C039), we have also checked (C041) "Work should always come first even if it means less spare time" and with (C008) on "Work vs Leisure". The results are qualitatively very similar.

${ }^{50}$ The Spearman correlation index displays a statistically significant negative correlation for all OECD countries and for all of the various questions on work values. Exceptions are, for C039, Germany and UK where the distribution of answers is strongly concentrated on the mode and does not display a large variation over skill levels.
} 
income inequality and the (absolute) magnitude of the correlation between skill levels and work motivation.

\section{Figure 5 About Here}

The picture also provides some support for the prediction that this negative relation should be nondecreasing with inequality. ${ }^{51}$

Concerning social attitudes, the model predicts that in cohesive economies individual social esteem will be uniformly allocated over the entire population, while in clustered economies higher inequality will produce an increasing bias in favor of the rich and against the poor. The model predicts that in cohesive economies, characterized by low dispersion in hours worked and inequality, we should see no bias against the poor, while in clustered economies we should see a negative bias, growing with the dispersion in labour supply.

Concerning the altruistic bias, we take the extent to which people attribute the cause of poverty to laziness as an indicator of lack of concern. Thus, we consider the extent to which people agree with the statement "Poverty is the result of laziness" ${ }^{52}$

\section{Figure 6 About Here}

Figure 6 displays a clear negative association between the concentration in hours worked (and hence inequality) and bias against the poor, as predicted by the model. Unfortunately, the number of countries included in this wave of the survey is quite limited. For the US and Australia, both displaying significant clustering, the share of the population that is biased against the poor is nearly three times that in Germany, Sweden or Finland. ${ }^{53}$

Given its limited nature, the purpose of this simple empirical exercise has not been to provide irrefutable evidence supporting our model, but rather to show that the available data exhibit patterns of inequality, redistribution, labour supply and individual attitudes that are broadly consistent with the model.

\section{Concluding remarks}

Let us conclude by briefly discuss the robustness of our results and the role played by our simplifying assumptions.

Following the literature in social psychology we have considered the case in which the emotions produced by the deviations from moral standards have a self-regulatory role. Consequently, we have assumed, in (15), that the $M R S$ between consumption and leisure is decreasing in $\varphi$ which implies that a drop in $\varphi$, due to the guilt associated to the failure of meeting the standards, increases the moral pressure to work. This self-regulation role of changes in self-esteem implies that moral values and economic incentives are substitutes. The resulting dynamics is stable and leads to work accordingly with the standards unless inequality is excessively large. For the sake of completeness, less momentarily entertain the possibility that moral and economic incentives

\footnotetext{
${ }^{51}$ Notice that the UK is an outlier in this case. The correlation is not significant for question C039 while it is negative and significant for question C041 (it takes value -0.175 , very similar to the one of US which is -0.197). We have worked with question C039 because it covered a larger number of countries.

${ }^{52}$ The phrasing of question (E131) is: "Why in your opinion are there people in this country who live in need? (1) Poor because of laziness and lack of will power. (2) Poor because of an unfair society."

${ }^{53}$ The data correspond to the following years: Australia 1995, Germany 1997, Finland 1996, Norway 1996, Sweden 1996 and US 1995. Similarly Alesina, Glaeser, and Sacerdote (2001) point out, using the World Values Survey, that while $60 \%$ of Americans believe the poor are lazy, only $26 \%$ of Europeans share this belief. Lamont (2000) documents that in both countries, for manual workers hard work is the main source of self-worth. She documents, however, important differences concerning the perception of others. While in France, manual workers value positively redistribution to the poor as a device to avoid social exclusion, the American counterparts explicitly state that the poor should not be supported because their situation is mainly due to their lack of effort.
} 
are complements, i.e. the $M R S$ between consumption and leisure is now decreasing in $\varphi$. In that case, a reduction in self-esteem, following from the failure to meet the standards, works as a negative rather than a positive pressure on labor supply. In spite of inverting the effects of guilt on labor supply, cohesive equilibria would still be possible only for low inequality and would vanish as soon as the difference in economic incentives is too large. The difference would be that now these cohesive equilibria are unstable so that the clustered equilibria become the absorbing state). ${ }^{54}$ Therefore the possibility to sustain cohesive equilibria with work standards does not depend on the substitutability between economic and moral incentives but rather on the relative strength of the two. This implies that the role of self-regulatory emotions is to insure the stability rather then the mere existence of cohesive equilibria.

Related to this point, notice that the politico-economic implications do not depend on the self-regulatory role of self-esteem. Assuming complementarity between moral pressure and wages would imply that the only stable equilibria are clustered. The degree of social clustering would be, however, increasing with inequality. This implies that, in particular, the non monotonicy of equilibrium redistribution, which is driven by the progressive increase of the bias in the allocation of social esteem, still emerges.

In our analysis of politico-economic equilibrium individual private utility was assumed to be additively separable and linear in income. This is common in the literature and in our view does not play a key role in establishing the qualitative results. The specific assumption concerning preferences for leisure does not seem to play a significant role either. Clearly, by assuming linearity of the total utility function, we have excluded an important impetus for redistribution, namely, inequality aversion. Hence, the equilibrium tax rates obtained in the paper are likely to be lower than if social preferences were strictly concave. Also, the nonmonotonicity of redistribution with respect to inequality, which is driven by the increasing bias in the allocation of social esteem, does not depend on the actual formulation of the utility function. The argument that in a cohesive equilibrium low productivity individuals should compensate for low monetary rewards with a higher sense of obligation clearly does not depend on the actual specification of individual preferences, nor does the fact that in clustered equilibrium the skilled workers would choose to work more than the unskilled.

As in Meltzer and Richard (1981) we have assumed that production is proportional to total effective labour supply. It is plain that nothing essential would change had we assumed output to be a strictly concave function of total effective labour. The implicit assumption of infinite substitutability among the different types of labour may be more significant. One might suspect that the degree of complementarity among different types of labour could play a role in the development of self-esteem as well as esteem for others. However, that is not the case. In a previous version of the paper we considered the entire class of CES production functions, and we established that the degree of substitutability has no effect on the qualitative results.

For simplicity, we have restricted our attention to two productivity types. The implication of including a larger number of types requires a more detailed discussion. Indeed, one might suspect that this is the main cause of the existence of a clustered socioeconomic equilibrium. We have explored this possibility in our earlier work. With additional types, the analysis becomes more complex and richer, but the main insights remain the same. With an arbitrary number of productivity levels, there still exist cohesive socioeconomic equilibria in which everyone conforms to the social norm. Also, clustered equilibria continue to exist, with a threshold type dividing those who work above the mean from those who work below. However, in this case, there may exist equilibria with a third cluster consisting of individuals with intermediate ability each supplying the mean quantity of labour. Such three-cluster equilibria are hybrids, exhibiting some

\footnotetext{
${ }^{54}$ In fact, in the appendix we show for the case with linear utility and complementarity, that the maximum level of inequality which allow to sustain cohesive equilibria is exactly the same as for the case of substitutability. These equilibria are, however, unstable and co-exists with stable clustering equilibria.
} 
of the attributes of cohesive equilibria and some of clustered equilibria. For those individuals who conform to the social norm, the relationship between monetary and moral rewards would be the same as in a cohesive equilibrium. Social concern would be inversely related to productivity. Also as in cohesive equilibrium, one finds that the range of productivities among those individuals conforming to the mean, hence the size of the group, depends on the degree of inequality in productivities and on the degree of redistribution.

Politico-economic equilibria are characterized similarly as for two types only. It can easily be verified that for the linear quadratic case, indirect preferences over tax rates are singlepeaked for any number of types. ${ }^{55}$ This guarantees the existence of a voting equilibrium with the equilibrium tax rate being that chosen by the median among the distribution of peaks. With general utility functions the determination of the voting equilibrium is substantially more complicated, and additional restrictions must be imposed to guarantee the existence of a majority rule equilibrium. In that case, while the main features of the different equilibria are unchanged, we cannot be certain that the comparative static analysis would be unaffected.

\footnotetext{
${ }^{55}$ Indirect utility is quadratic in $\tau$ and strictly decreasing at $\tau=1$. This rules out any source of non-singlepeakedness.
} 


\section{References}

Acemoglu, D. (2003): "Cross Country Inequality Trends," The Economic Journal, 113, 121149.

Akerlof, G., and R. Kranton (2004): "Identity and the Economics of Organization," Journal of Economic Perspectives, 19(1), 9-32.

Alesina, A., and G. M. Angeletos (2005): "Fairness and Redistribution," American Economic Review, 95(4), 913-935.

Alesina, A., E. Glaeser, and B. Sacerdote (2001): "Why Doesn't the United States Have a European-Style Welfare State?," Brooking Papers on Economic Activity, 2, 187-278.

(2005): "Work and leisure in the U.S. and Europe: Why so different?" NBER Macroeconomic Annual, pp. 1-64.

Alesina, A., and E. L. Glaeser (2004): Fighting Poverty in the U.S. and Europe: A World of Difference. to appear in: Oxford University Press, Oxford.

Alesina, A., and E. La Ferrara (2005): "Preferences for Redistribution in the Land of Opportunities," Journal of Public Economics, 89(5), 897-931.

Autor, D. H., L. F. Katz, and M. S. Kearney (2006): "The Polarization of the U.S. Labor Market," American Economic Review, 96(2), 189-194.

Baumeister, R. F., A. M. Stillwell, and T. F. Heatherton (1994): "Guilt: An Interpersonal Approach," Psychological Bulletin, 115, 243-267.

Bénabou, R. (1996): "Inequality and Growth," NBER Macroeconomic Annual, Bernanke B. and Rotemberg J.J. Eds Cambridge and London MIT Press, pp. 11-74.

(2000): "Unequal Societies: Income Distribution and the Social Contract," American Economic Review, 90, 96-129.

(2002): "Self-Confidence and Personal Motivation," Quarterly Journal of Economics, $117(3), 871-915$.

Bénabou, R., and E. Ok (2001): "Social Mobility and the Demand for Redistribution: The POUM Hypothesis," Quarterly Journal of Economics, 116, 447-487.

Bénabou, R., and J. Tirole (2002): Self-Knowledge and Self-Regulation: An Economic Approach. The Psychology of Economic Decisions: Volume One: Rationality and Well-Being, I. Brocas and Juan Carrillo, eds., Oxford University Press.

(2003): "Intrinsic and Extrinsic Motivation," Review of Economic Studies, 70, 489-520.

(2005): "Belief in a Just World and Redistributive Politics," The Quarterly Journal of Economics, 121(2), 699-746.

1652-1678. 
Besley, T., and S. Coate (1992): "Understanding Welfare Stigma: Taxpayer Resentment and Statistical Discrimination," Journal of Public Economics, 48(2), 165-183.

Bisin, A., And T. Verdier (2004): "Work Ethic and Redistribution: A cultural Transmission Model of the Welfare State," mimeo NYU.

Brekke, K., S. Kverndokk, and K. Nyborg (2003): "An Economic Model of Moral Motivation," Journal of Public Economics, 87(9), 1967-1983.

Burda, M. C., D. S. Hamermesh, and P. Weil (2006): "The Distribution of Total Work in the EU and US," IZA Discussion Paper 2270.

Cialdini, R. B., C. Kallgren, and R. Reno (1991): "A Focus Theory of Normative Conduct: A Theoretical Refinement and Reevaluation of the Role of Norms and Human Behavior," Advances in Experimental Social Psychology, 21, 201-234.

Corneo, G., And H. P. GrÜner (2000): "Social limits to redistribution," American Economic Review, 90, 1491-1507.

(2002): "Individual Preferences for Political Redistribution," Journal of Public Economics, 83, 83-107.

Crocker, J., and L. E. Park (2003): "Seeking Self-Esteem: Construction, Maintainance and Protection of Self-Worth," Handbook of Self and Identity, M. Leary and J. Tangney Eds NY Guilford, pp. 291-313.

De Mello, L., and E. R. Tiongson (2006): "Income Inequality and Redistributive Government Spending," Public Finance Review, 34(3), 282-305.

Deci, E.-L. (1971): "Effects of Externally Mediated Rewards on Intrinsic Motivation," Journal of Personality and Social Psychology, 18, 105-115.

Devroye, D., and R. Freeman (2001): "Does Inequality in Skills Explain Inequality of Earnings Across Countries," NBER wp 8140.

Duncan, G., T. Smeeding, and W. Rodgers (1991): "W(h)ither the Middle Class? A Dynamic View," Levy Institute Conference on Income Inequality, Bard College.

Eisenberg, N. (1986): Altruistic Cognition, Emotion and Behavior. Erlbaum, Hillsdale, NJ.

Elster, J. (1989): "Social Norms and Economic Theory," Journal of Economic Perspectives, $3,99-117$.

Esteban, J. M., and D. Ray (1994): "On the Measurement of Polarization," Econometrica, $62,819-852$.

Fong, C. (2001): "Social Preferences, Self-Interest and the Demand for Redistribution," Journal of Public Economics, 82, 225-246.

Freedman, J. L., S. A. Wallington, and E. Bless (1967): "Compliance Without Pressure: The Effect of Guilt," Journal of Personality and Social Psychology, 7.

Frey, B. (1997): "Not Just for the Money. An Economic Theory of Personal Motivation," Edward Elgar.

Frey, B., And R. Jegen (2001): "Motivation Crowding Theory," Journal of Economic Surveys, $15,589-611$. 
Gneezy, U., And A. Rustichini (2001): "Pay Enough or Don’t Pay At All," Quarterly Journal of Economics, 115, 791-810.

GrÜner, H. P., And R. Schils (2006): "The Political Economy of Wealth and Interest," Economic Journal, forthcoming.

Hassler, J., J. Rodríguez Mora, K. Storesletten, and F. Zilibotti (2003): "The Survival of the Welfare State," American Economic Review, 93, 87-112.

Horrigan, M., and S. Haugen (1988): "The Declining Middle Class Thesis: A Sensitivity Analysis," Monthly Labour Review, 111, 3-13.

Inglehart, R., And Et AL Editors (2004): "Human Beliefs and Values: A cross-cultural sourcebook based on the 1999-2002 values surveys," Siglo XXI Editores Mexico.

Katz, L., And D. Autor (1999): "Changes in the Wage Structure and Earnings Inequality," Handbook of Labor Economics North Holland O. Ashenfelter and D. Card Eds, 3, 1463-1555.

Kinder, D., and D. Sears (1998): "Public Opinion and Political Action," Handbook of Social Psychology 4th Edition, by G. Lindzey and E. Aronson Eds. Vol 2, pp. 480-491.

Kosters, M., and M. Ross (1988): "A Shrinking Middle Class?," The Public Interest, 90, $3-27$.

Kranich, L. (2001): "Altruism and the Political Economy of Income Taxation," Journal of Public Economic Theory, 3(4), 455-469.

Kreps, D. (1997): "Intrinsic Motivation and Extrinsic Incentives," American Economic review, 87, 359-364.

Kuhn, P., And F. Lozano (2005): "The Expanding Workweek? Understanding Trends in Long Work Hours Among U.S. Men, 1979-2004," NBER Working Paper 11898.

Lamont, M. (2000): "The Dignity of the Working Men: Morality and the Boundaries of Race, Class, and Immigration," Harvard University Press.

Latham, G. P., and G. C. Pinder (2005): "Work Motivation Theory and Research at the Dawn of the Twenty-First Century," Annual Review of Psychology, 56, 485-516.

Lindbeck, A., And S. Nyberg (2006): "Raising Children to Work Hard: Altruism, Work Norms and Social Insurance," Quarterly Journal of Economics, 121(4), 1473-1503.

Lindbeck, A., S. Nyberg, and J. Weibull (1999): "Social Norms and Economic Incentives in the Welfare State," The Quarterly Journal of Economics, 114, 1-35.

- (2003): "Social Norms and Welfare State Dynamics," Journal of the European Economic Association, pp. 533-542.

Lukes (1973): Individualism. Oxford Blackwell.

Luttmer, Erzo, F. P. (2001): "Group Loyalty and the Taste for Redistribution," Journal of Political Economy, 109(3), 500-528.

Meltzer, A. H., and S. F. Richard (1981): "A Rational Theory of the Size of Government," Journal of Political Economy, 89(5), 914-927. 
Milanovic, B. (2000): "The median-voter hypothesis, income inequality, and income redistribution: an empirical test with the required data," European Journal of Political Economy, 16(3), 367-410.

Moffit, R. (1983): "An Economic Model of Welfare Stigma," American Economic Review, 73(5), 1023-1035.

Murdock, K. (2002): "Intrinsic Motivation and Optimal Incentive Contracts," Rand Journal of Economics, 33, 650-671.

OECD (2004): "Employment Outlook," OECD.

Perotti, R. (1996): "Growth, Income Distribution and Democracy: What the Data Say," Journal of Economic Growth, 1, 149-187.

Piketty, T. (1995): "Social Mobility and Redistributive Politics," Quarterly Journal of Economics, 60, 551-583.

Prescott, E. (2004): "Why do Americans Work so Much More Than Europeans?," Federal Reserve Bank of Minneapolis Quarterly Review, 28(1), 121-149.

Roberts, K. W. S. (1977): "Voting Over Income Tax Schedules," Journal of Public Economics, $8,329-340$.

Rodriguez, F. C. (1999): "Does Distributional Skewness Lead to Redistribution? Evidence from the United States," Economics and Politics, 11(2), 171-199.

Rogerson, R. (2005): "Structural Transformation and the Deterioration of European Labor Markets Outcomes," mimeo.

Rokeach (1973): The Nature of Human Values. New York -Free Press, New York.

Romer, T. (1975): "Individual Welfare, Majority Voting and the Properties of the Linear Income Tax," Journal of Public Economics, 4(4), 163-185.

Rubery, J., M. Smith, and C. Fagan (1998): "National Working-Time Regimes and Equal Opportunities," Feminist Economics, 4(1), 71-101.

Schwartz, S. H. (1977): Normative Influence on Altruism, vol. 10. Advances in Experimental Social Psychology, L. Berkowitz Ed., Academic Press, New York.

Schwartz, S. H., And J. Howard (1982): Helping and Cooperation: A Self Based Motivational Model. Cooperation and Helping Behavior, V. Derlega and H. Grezlak (Eds), Academic Press, New York.

Snyder, J., and G. Kramer (1988): "Fairness, Self-Interest, and the Politics of the Progressive Income Tax," Journal of Public Economics, 36, 197-230.

Tangney, J. P. (1995): Shame and Guilt in Interpersonal Relationships. Guilford Press, New York.

(2002): "Self-Relevant Emotions," Handbook of Self and Identity, Mark R. Leary, June Price Tangney and Geoff MacDonald Eds. Guilford Press, pp. 384-400.

Tangney, J. P., and R. L. Dearing (2002): Shame and Guilt. Guilford Press, New York.

Wolfson, M. (1994): "When Inequalities Diverge," American Economic Review Papers and Proceedings, 84, 353-358. 


\section{Appendix. Proofs and Figures}

Proof of Proposition 1. Given that labour supply is monotonically increasing in individual productivity $\beta_{i}$ from (20), we know that $\underline{L}_{u}\left(\tau, \beta_{u}, \beta\right)<\underline{L}_{s}\left(\tau, \beta_{s}, \beta\right)$ and $\bar{L}_{u}\left(\tau, \beta_{u}, \beta\right)<$ $\bar{L}_{s}\left(\tau, \beta_{s}, \beta\right)$.

It is necessary and sufficient for the existence of a cohesive equilibrium that $\bar{L}_{u}\left(\tau, \beta_{u}, \beta\right) \geq$ $\underline{L}_{s}\left(\tau, \beta_{s}, \beta\right)$, i.e., that there is some $L$ that satisfies (17) for both $u$ and $s$ at $T=\tau \beta L$ and that every such $L$ is a cohesive SE equilibrium labour supply in which $\left(\varphi_{u}, \varphi_{s}\right)$ solves (23) for $i=u, s$. We next show that under these conditions clustered equilibria cannot emerge. Suppose $\bar{L}_{u}\left(\tau, \beta_{u}, \beta\right) \geq \underline{L}_{s}\left(\tau, \beta_{s}, \beta\right)$ and, to the contrary, suppose there is also a clustered equilibrium in which $L=\left(L_{u}, L_{s}\right), L_{u} \neq L_{s}$. First, if $L_{u}<L_{s}$, since this is stationary, it must be that $\varphi_{u}=\underline{\varphi}$ and $\varphi_{s}=\bar{\varphi}$. But then $L_{u}=\bar{L}_{u}\left(\tau, \beta_{u}, \beta\right)$ and $L_{s}=\underline{L}_{s}\left(\tau, \beta_{s}, \beta\right)$, which contradicts $\bar{L}_{u}\left(\tau, \beta_{u}, \beta\right)>$ $\underline{L}_{s}\left(\tau, \beta_{s}, \beta\right)$. Alternatively, if $L_{u}>L_{s}$, then in this case stationarity implies $\varphi_{u}=\bar{\varphi}$ and $\varphi_{s}=\underline{\varphi}$. Hence, $L_{u}=\underline{L}_{u}\left(\tau, \beta_{u}, \beta\right)$ and $L_{s}=\bar{L}_{s}\left(\tau, \beta_{s}, \beta\right)$. Therefore, $\underline{L}_{u}\left(\tau, \beta_{u}, \beta\right)>\bar{L}_{s}\left(\tau, \beta_{s}, \beta\right)$. Since $\bar{L}_{s}\left(\tau, \beta_{s}, \beta\right)>\bar{L}_{u}\left(\tau, \beta_{u}, \beta\right)$, as shown above, this implies $\underline{L}_{u}\left(\tau, \beta_{u}, \beta\right)>\bar{L}_{u}\left(\tau, \beta_{u}, \beta\right)$, which is also a contradiction. It remains to be shown that $\bar{L}_{u}\left(\tau, \beta_{u}, \beta\right)<\underline{L}_{s}\left(\tau, \beta_{s}, \beta\right)$ is sufficient for the existence of a clustered equilibrium. However, if $\bar{L}_{u}\left(\tau, \beta_{u}, \beta\right)<\underline{L}_{s}(\tau, \beta s, \beta)$ and $\varphi_{u}=\underline{\varphi}$ and $\varphi_{s}=\bar{\varphi}$, then the conditions of the definition of a clustered SE equilibrium are clearly satisfied. Finally, compatible values of $\alpha$ can be derived from (14) and (11) as stated in the Proposition.

Proof of Proposition 3. (i) Rearrange (30) to get

$$
\frac{\partial v_{u}}{\partial c}\left(1+\alpha_{u}\left(1-\sigma_{u}\right)\right)\left[y-y_{u}+\tau \frac{d y}{d \tau}\right]=-\sigma_{u} \alpha_{u} \frac{\partial v_{s}}{\partial c}\left[y-y_{s}+\tau \frac{d y}{d \tau}\right] .
$$

Since the RHS of this is positive, the LHS must be positive as well which implies

$$
y-y_{u}+\tau \frac{d y}{d \tau}>0 .
$$

If that is the case, then from (29) $\frac{d \nu_{u}}{d \tau}>0$ at $\tau^{u}$. Hence $\tau^{u}<\tau^{m}$, or the level of redistribution preferred by the poor is smaller than in the egoistic case.

A larger $\alpha_{u}$ increases the weight of the social part relative to the egoistic one and accordingly reduces the demand for taxation on the part of the poor in any interior optimum. From implicit differentiation we have,

$$
\begin{aligned}
\operatorname{sign} \frac{\partial \tau^{u}}{\partial \alpha_{u}} & =\operatorname{sign}\left(-\frac{\partial^{2} V_{u} / \partial \tau \partial \alpha_{u}}{\partial^{2} V_{u} / \partial \tau^{2}}\right)= \\
& =\operatorname{sign}\left\{\left(1-\sigma_{u}\right) \frac{\partial v_{u}}{\partial c}\left[y-y_{u}+\tau \frac{d y}{d \tau}\right]+\sigma_{u} \frac{\partial v_{s}}{\partial c}\left[y-y_{s}+\tau \frac{d y}{d \tau}\right]\right\}
\end{aligned}
$$

from (54) and from (30) noting that $\partial^{2} V_{u} /\left.\partial \tau^{2}\right|_{\tau^{u}}<0$ by (31) we have that

$$
\frac{\partial \tau^{u}}{\partial \alpha_{u}}<0
$$

(ii) As for the preferences of the skilled workers we have that

$$
\frac{\partial v_{s}}{\partial c}\left(1+\alpha_{s} \sigma_{s}\right)\left[y-y_{s}+\tau \frac{d y}{d \tau}\right]+\left(1-\sigma_{s}\right) \alpha_{s} \frac{\partial v_{u}}{\partial c}\left[y-y_{u}+\tau \frac{d y}{d \tau}\right] \leq 0 .
$$

Since $\left[y-y_{s}+\tau \frac{d y}{d \tau}\right]<0$, a purely egoistic skilled worker would optimally choose $\tau=0$ (from the analogue of (29) for $s$ ). The same is true if $s$ is altruistic but the inequality in (55) is strict. 
In that case, after taking into consideration the effects of taxation on both the egoistic and the social components of utility, the skilled workers would continue to oppose redistribution. However, if (55) holds with equality, then

$$
\frac{\partial v_{s}}{\partial c}\left(1+\alpha_{s} \sigma_{s}\right)\left[y-y_{s}+\tau \frac{d y}{d \tau}\right]=-\left(1-\sigma_{s}\right) \alpha_{s} \frac{\partial v_{u}}{\partial c}\left[y-y_{u}+\tau \frac{d y}{d \tau}\right] .
$$

As in (i), this implies $\left[y-y_{u}+\tau \frac{d y}{d \tau}\right]>0$ at the solution $\tau^{s}$. Hence $\tau^{s}<\tau^{m}$ as well. Next we show that $\tau^{u}>\tau^{s}$ even in the case in which $\tau^{s}>0$, that is, when (56) holds with equality. Now, we compare the coefficients of the positive expression $\frac{\partial v_{u}}{\partial c}\left[y-y_{u}+\tau \frac{d y}{d \tau}\right]$ in (56) and (53). By (8) and (12), $\sigma_{u}=\sigma_{s}$ in a stationary equilibrium, and by definition, $0 \leq 1-\sigma_{u} \leq 1$. Also, the maximal feasible range of $\left(\alpha_{s}-\alpha_{u}\right)$ is $-1<\alpha_{s}-\alpha_{u}<1$. Therefore, $1+\alpha_{u}\left(1-\sigma_{u}\right)>\left(1-\sigma_{s}\right) \alpha_{s}$. Alternatively, comparing the coefficients of the negative expression $\frac{\partial v_{s}}{\partial c}\left[y-y_{s}+\tau \frac{d y}{d \tau}\right]$, we have that $1+\alpha_{s} \sigma_{s}>\alpha_{u} \sigma_{u}$. Taken together, these imply that in (30), $\frac{d V_{u}(\tau)}{d \tau}>0$ at $\tau^{s}$. Hence, $\tau^{u}>\tau^{s} \geq 0$.

Proof of Proposition 4 and Proposition 5. The first order condition for labour supply can be expressed as

$$
\left[(1-\tau) \beta_{i} L_{i}+T\right]^{-\theta}(1-\tau) \beta_{i}=f^{\prime}\left(\bar{L}-L_{i}\right) \varphi_{i}
$$

Therefore in a cohesive SE equilibrium where $L_{i}=L$ for all $i$, and $T=\tau \beta L$, this can be written as

$$
f^{\prime}(\bar{L}-L) L^{\theta}=\left(1 / \varphi_{i}\right)\left[(1-\tau) \beta_{i}+\tau \beta\right]^{-\theta}(1-\tau) \beta_{i},
$$

where the $L H S$ is strictly increasing in $L$ while the $R H S$ is independent of $L$. From this expression, we have that (25) in Proposition 1 holds if and only if

$$
(1 / \underline{\varphi})\left[(1-\tau) \beta_{u}+\tau \beta\right]^{-\theta} \beta_{u} \geq(1 / \bar{\varphi})\left[(1-\tau) \beta_{s}+\tau \beta\right]^{-\theta} \beta_{s} .
$$

Rearranging the last expression, we have that a cohesive SE equilibrium exists if and only if

$$
\left(\frac{\beta_{u}}{\beta_{s}}\right)^{1 / \theta} \geq\left(\frac{\underline{\bar{\varphi}}}{\bar{\varphi}}\right)^{1 / \theta}\left[\frac{(1-\tau) \beta_{u}+\tau \beta}{(1-\tau) \beta_{s}+\tau \beta}\right]
$$

After some manipulation (57) can be rewritten as

$$
\begin{aligned}
(\underline{\underline{\varphi}})^{1 / \theta}(\widetilde{\beta})^{1 / \theta} & \geq\left[\frac{\widetilde{\beta}(1-\tau)+\tau((1-\pi) \widetilde{\beta}+\pi)}{(1-\tau)+\tau((1-\pi) \widetilde{\beta}+\pi)}\right]= \\
& =\frac{\widetilde{\beta}(1-\tau)+\tau((1-\pi) \widetilde{\beta}+\pi) \pm(1-\tau)}{(1-\tau)+\tau((1-\pi) \widetilde{\beta}+\pi)}= \\
& =1-\frac{(1-\tau)}{(1-\tau)+\tau((1-\pi) \widetilde{\beta}+\pi)},
\end{aligned}
$$

which can finally be expressed as

$$
H(\widetilde{\beta}) \equiv(\widetilde{\beta})^{1 / \theta} \geq\left(\frac{\underline{\bar{\varphi}}}{\varphi}\right)^{1 / \theta}\left\{1-\frac{(1-\widetilde{\beta})}{1+(\tau /(1-\tau))((1-\pi) \widetilde{\beta}+\pi)}\right\} \equiv G(\widetilde{\beta}, \tau)\left(\frac{\underline{\bar{\varphi}}}{\varphi}\right)^{1 / \theta} .
$$


Consider the RHS and the LHS of (59) in the space $\widetilde{\beta} \in[0,1]$. First, $H($.$) is strictly$ increasing and either strictly concave for $\theta>1$, strictly convex for $\theta<1$, or linear for $\theta=1$. Also, $H(0)=0$ and $H(1)=1$.

Notice that $G(\widetilde{\beta}, \tau)$ is strictly increasing in $\tau$ with $G(\widetilde{\beta}, 0)=\widetilde{\beta}$ and $G(\widetilde{\beta}, 1)=1$. In particular denote by $\widetilde{\beta}_{1}$ the level of relative productivity such that (59) is satisfied with equality for $\tau=1$. This is given by

$$
\widetilde{\beta}_{1}=\frac{\varphi}{\bar{\varphi}}<1 .
$$

Also, denote by $\widetilde{\beta}_{0} \in[0,1]$ the relative productivity at which (59) is satisfied with equality for $\tau=0$, which is given by ${ }^{56}$

$$
\widetilde{\beta}_{0}=\left(\frac{\underline{\underline{\varphi}}}{\bar{\varphi}}\right)^{\frac{1}{1-\theta}}<1 \text { for any } \theta \leq 1 \text { and } \widetilde{\beta}_{0}=0 \text { for any } \theta>1 \text {. }
$$

Clearly, for $\theta>1, \widetilde{\beta}_{1}>\widetilde{\beta}_{0}$. But also for $\theta \leq 1$, since $\frac{\varphi}{\bar{\varphi}}<1$ and $\frac{1}{1-\theta}>1, \widetilde{\beta}_{1}>\widetilde{\beta}_{0}$. Therefore we have an upper bound $\widetilde{\beta}_{1}$ (that is, a lower bound for inequality) such that for any $\widetilde{\beta} \geq \widetilde{\beta}_{1}$ only cohesive SE equilibria exist and a lower bound $\widetilde{\beta}_{0}$ such that for any $\widetilde{\beta}<\widetilde{\beta}_{0}$ only clustered SE equilibria exist. This proves Proposition 5.

Proposition 4 is proved by noting that by the monotonicity of $G(\widetilde{\beta}, \tau)$ in $\tau$ and the Intermediate Value Theorem, for any $\widetilde{\beta}^{\prime} \in\left[\widetilde{\beta}_{0}, \widetilde{\beta}_{1}\right]$ there always exists a unique interior $\bar{\tau}\left(\widetilde{\beta}^{\prime}\right)$ such that if $\tau>\bar{\tau}\left(\widetilde{\beta}^{\prime}\right)$, then only clustered equilibria are possible, while if $\tau \leq \bar{\tau}\left(\widetilde{\beta}^{\prime}\right)$, only cohesive equilibria exist. Also the larger $\widetilde{\beta}^{\prime}$ the larger the required $\tau$ necessary to make the functions $H(\widetilde{\beta})$ and $G(\widetilde{\beta}, \tau)\left(\frac{\underline{\underline{\varphi}}}{\varphi}\right)^{1 / \theta}$ cross exactly at $\widetilde{\beta}^{\prime}$.

Proof of Proposition 7. Substituting $I^{*}$ from (47) into (49) and restricting attention to the distributions of sentiments compatible with cohesive equilibrium, we obtain the equilibrium level of redistribution $\tau^{*}=\left(\beta-\beta_{u}\right) /\left(2 \beta-\beta_{u}+\alpha_{u} \beta\right)$. This tax rate must be jointly compatible with optimal labour supply. Hence, using this expression for $\tau^{*}$ together with (35) we obtain the expression for the locus

$$
T T: L=\left(1-\tau^{*}\right)^{2} \beta_{u}\left(\beta-\beta_{u}\right) /\left(\tau^{*} \beta\right),
$$

which is a strictly decreasing function for $\tau^{*}<1$ which takes infinite value and slope at $\tau^{*}=0$ and zero value and slope at $\tau^{*}=1$.

Note that (61) can be written as

$$
L=\left(1-\tau^{*}\right)^{2} \beta_{u} I / \tau^{*} .
$$

This implies that whenever condition (46) is satisfied then $\widehat{\alpha}_{u}(I) \leq 1$, and for any $\alpha_{u} \in$ $\left[\widehat{\alpha}_{u}(I), 1\right]$ there exists a unique vector $\left(L_{u}\left(\alpha_{u}\right), \tau^{c}\left(\alpha_{u}\right)\right)$ in which $L_{i}\left(\alpha_{i}\right)=L\left(\alpha_{u}\right)$ satisfies the first order condition for optimal labour supply (35) for $i=u, s$, and $\tau^{c}\left(\alpha_{u}\right)$ is the equilibrium tax rate (44). The computation of the extreme values of $\tau$ in (51) is straightforward.

Proof of Lemma 2. The range of inequality $I$ for which the economy is in a cohesive/clustered SE equilibrium is characterized in Propositions 7 and 8. From (10) and (35), in any clustered equilibrium the bias in social sentiments is given by

$$
\sigma_{u}=\frac{\pi \beta_{u}}{(1-\pi) 2 \beta_{u}+\pi \beta_{s}} .
$$

\footnotetext{
${ }^{56}$ One solution is always $\widetilde{\beta}_{0}=0$ while the second solution is in the range $[0,1]$ only if $\theta \leq 1$.
} 
In this case the magnitude of the distributive bias $\delta$ is given by

$$
\delta=\frac{\left(y-\widetilde{y}_{u}\right)}{y}=\frac{(1-\pi) 2 \beta_{u}^{2}+\pi \beta_{s}^{2}-\left(1-\sigma_{u}\right) 2 \beta_{u}^{2}-\sigma_{u} \beta_{s}^{2}}{(1-\pi) 2 \beta_{u}^{2}+\pi \beta_{s}^{2}} .
$$

Using (63) and rearranging, we can express the numerator of (64) as

$$
\begin{aligned}
(1-\pi) 2 \beta_{u}^{2}+\pi \beta_{s}^{2}-2 \beta_{u}^{2}+\frac{\pi \beta_{s}}{(1-\pi) 2 \beta_{u}+\pi \beta_{s}}\left(2 \beta_{u}^{2}-\beta_{s}^{2}\right) & = \\
\pi\left(\beta_{s}^{2}-2 \beta_{u}^{2}\right)\left(1-\frac{\beta_{s}}{(1-\pi) 2 \beta_{u}+\pi \beta_{s}}\right) & =-\frac{\pi(1-\pi)\left(\beta_{s}^{2}-2 \beta_{u}^{2}\right)\left(\beta_{s}-2 \beta_{u}\right)}{(1-\pi) 2 \beta_{u}+\pi \beta_{s}} .
\end{aligned}
$$

Therefore,

$$
\delta(I)=-\pi(1-\pi) \frac{1-2 \widetilde{\beta}}{(\pi+(1-\pi) 2 \widetilde{\beta})} \frac{1-2 \widetilde{\beta}^{2}}{\left(\pi+(1-\pi) 2 \widetilde{\beta}^{2}\right)}<0 \text { for } \widetilde{\beta}<\frac{1}{2} .
$$

Computing the level of income inequality one gets

$$
I=\frac{\pi\left(1-2 \widetilde{\beta}^{2}\right)}{\left(\pi+(1-\pi) 2 \widetilde{\beta}^{2}\right)},
$$

which implies

$$
\delta=-(1-\pi) I \frac{1-2 \widetilde{\beta}}{(\pi+(1-\pi) 2 \widetilde{\beta})}<0 .
$$

From (65) we have

$$
\frac{\partial I}{\partial \widetilde{\beta}}=-\frac{4 \pi \widetilde{\beta}}{\left(\pi+(1-\pi) 2 \widetilde{\beta}^{2}\right)^{2}}<0
$$

The bias in social sentiments is increasing in $I$ since

$$
\begin{aligned}
\frac{\partial \delta}{\partial I} & =-(1-\pi) \frac{1-2 \widetilde{\beta}}{(\pi+(1-\pi) 2 \widetilde{\beta})}+I \frac{\partial}{\partial \widetilde{\beta}}\left(-(1-\pi) \frac{1-2 \widetilde{\beta}}{(\pi+(1-\pi) 2 \widetilde{\beta})}\right) \frac{\partial \widetilde{\beta}}{\partial I}= \\
& =\frac{\delta}{I}+2 I(1-\pi) \frac{\partial \widetilde{\beta}}{\partial I}<0,
\end{aligned}
$$

which proves the statement.

Proof of Proposition 9. (i) For the minimum equilibrium tax rate in any cohesive PE equilibrium, $\tau_{m}^{*}$, the statement follows by simple differentiation. Substituting for $K^{*}$ in (52), the maximum tax rate is

$$
\tau_{M}^{*}=\frac{I}{\frac{I+\pi(1-I)}{\pi(1-I)}+I}=\frac{\pi I(1-I)}{I+\pi(1-I)+\pi I(1-I)}=\frac{\pi}{A+\pi}
$$

where $A=\left(\frac{1}{1-I}+\frac{\pi}{I}\right)$. Hence,

$$
\frac{\partial \tau_{M}^{*}}{\partial I}=-\frac{\pi}{(\pi+A)^{2}} \frac{\partial A}{\partial I}
$$


where $\frac{\partial A}{\partial I}=\frac{1}{(1-I)^{2}}-\frac{\pi}{I^{2}}$.

For the maximum $I$ compatible with cohesive PE equilibrium, namely, $\bar{I}=\frac{\pi}{1-\pi}$, we have $\frac{\partial A(\bar{I})}{\partial I}=\frac{1}{(1-I)^{2}}\left(1-\frac{1}{\pi}\right)<0$. Since $\frac{\partial^{2} A}{\partial I^{2}}=\frac{2}{(1-I)^{3}}+\frac{2 \pi}{I^{3}}>0$, this is sufficient to show $\frac{\partial \tau_{M}^{*}}{\partial I}>0$ for all $I \leq \bar{I}$.

(ii) From Lemma 2, in clustered equilibrium $\delta(I)<0$ and $\frac{\partial \delta}{\partial I}<0$. And from Proposition 8 the equilibrium level of redistribution is $\tau(I)=\frac{\delta+I}{2+\delta+I}$. Therefore,

$$
\frac{\partial \tau^{o}}{\partial I}=\frac{1}{(2+\delta+I)^{2}}\left(1+\frac{\partial \delta}{\partial I}\right) \gtrless 0 \Longleftrightarrow 1 \gtrless\left|\frac{\partial \delta}{\partial I}\right| .
$$

Recall that $I=\bar{I}=\frac{\pi}{1+\pi} \Leftrightarrow \widetilde{\beta}=1 / 2$, and $\delta(\bar{I})=0$. Then from (66) evaluated at $\widetilde{\beta}=1 / 2$ we obtain

$$
\left.\frac{\partial \widetilde{\beta}}{\partial I}\right|_{I=\bar{I}}=-\frac{(1+\pi)^{2}}{8 \pi} .
$$

Hence, from (67) we have $\left.\frac{\partial \tau^{o}}{\partial I}\right|_{I=\bar{I}}=\frac{1}{(2+\bar{I})^{2}}\left(\frac{3-\pi^{2}}{4}\right)>0$. Notice also that from Proposition 8 , there exists a level of inequality $I^{\prime}>\bar{I}$ such that $\tau^{o}=0$. Hence, by continuity of $\tau^{o}(I)$ and by Intermediate Value Theorem there exists a level $I^{s}$ for which $\tau^{o}$ is maximal.

Redistribution as a function of the Gini Index. From Proposition 9 we know that redistribution is maximal for some $I>\bar{I}$ and the maximum value it is implicitly characterized by maximizing (44). Denote the preferred level of redistribution as function of inequality as $\tau=\phi(I)$. Differentiating, we have

$$
d \tau=\phi^{\prime}(I) d I .
$$

Computing the Gini index for disposable income, we get $G=(1-\tau)(1-\pi) I$. By totally differentiating we have

$$
d I=\frac{1}{(1-\tau)(1-\pi)} d G+\frac{G}{(1-\tau)^{2}(1-\pi)} d \tau .
$$

Substituting and rearranging,

$$
d \tau\left[1-\frac{\phi^{\prime}(I) G}{(1-\tau)^{2}(1-\pi)}\right]=d G \frac{\phi^{\prime}(I)}{(1-\tau)(1-\pi)} .
$$

Therefore,

$$
\frac{d \tau}{d G}=\frac{\phi^{\prime}(I)(1-\tau)}{(1-\tau)^{2}(1-\pi)-\phi^{\prime}(I) G}=0 \Leftrightarrow \phi^{\prime}(I)=0,
$$

which implies that the change in redistribution as a function of the Gini index co-moves with the change in pre-tax income inequality $I$.

Self-esteem and labor supply. To illustrate the role of regulatory function of selfconscious emotions, consider the case in which moral motivation and wages are complements rather than substitute. Contrary to (15) assume instead that:

$$
\frac{d}{d \varphi_{i}}\left(\frac{v_{l}}{v_{c}}\right)<0
$$

In the case of linear-quadratic utility function adopted in Section 5 this can be formalized by assuming that,

$$
v\left(c_{i}, L_{i}, \varphi_{i}\right)=c_{i}+\left(1-\frac{L_{i}^{2}}{2}\right) \frac{1}{\varphi_{i}}
$$


which delivers an optimal labor supply,

$$
L_{i}\left(\beta_{i}, \varphi_{i}, \tau\right)=(1-\tau) \beta_{i} \varphi_{i}
$$

instead of $L_{i}\left(\beta_{i}, \varphi_{i}, \tau\right)=(1-\tau) \frac{\beta_{i}}{\varphi_{i}}$. Therefore $\varphi$ and $\beta$ are complements rather than substitute for labor effort. This implies that an increase in self-esteem $\varphi$ leads to an increase rather than a reduction in labor supply. In this case the maximum labor supply, for any $\beta_{i}$, is attained at $\varphi_{i}=\bar{\varphi}$ rather than at $\varphi_{i}=\underline{\varphi}$ as in the text.

From the Proof of Proposition 5 we know that for the utility formulation (33) there exists a maximum level of productivity ratio given by

$$
\widetilde{\beta}_{1} \equiv \frac{\beta_{u}}{\beta_{s}}=\frac{\varphi}{\bar{\varphi}}
$$

such that for any $\widetilde{\beta}>\widetilde{\beta}_{1}$ only cohesive equilibria exists while for any $\widetilde{\beta}<\widetilde{\beta}_{1}$ only clustered equilibria exists. Repeating the logic of the argument with the utility formulation (71) we have that in a cohesive equilibrium it must be,

$$
L_{u}\left(\beta_{u}, \varphi_{u}, \tau\right)=L_{u}\left(\beta_{u}, \varphi_{u}, \tau\right) \Longleftrightarrow \beta_{u} \varphi_{u}=\beta_{s} \varphi_{s}
$$

As in the text an increase in the productivity spread leads skilled workers to work relative more. This can be compensated, however, by a reduction in their self-esteem. Therefore a cohesive equilibrium can be sustained as long as

$$
\beta_{u} \bar{\varphi} \geq \beta_{s} \underline{\underline{\beta}} \equiv \frac{\beta_{u}}{\beta_{s}} \geq \frac{\underline{\bar{\varphi}}}{\bar{\varphi}}
$$

which is the same threshold as in the case considered in the text. This implies that cohesive equilibria can be sustained only if inequality in productivity is not too large. What allows to sustain cohesive equilibria is not the substitutability between economic and moral incentives but rather on relative strength between the two. Notice however that a cohesive equilibrium as (73) is not stable. Any deviation leads dynamically to a clustered equilibrium. Consider e.g. the case in which $L_{s}>L_{u}$. From the dynamic evolution of self-esteem and social esteem (12) and (13) this leads to an increase in $\varphi_{s}$ and a decrease in $\varphi_{u}$. As result we observe a further increase in the gap $L_{s}-L_{u}$. The process continues until a clustered equilibrium with $\varphi_{s}=\bar{\varphi}, \varphi_{u}=\underline{\varphi}$ and $L_{s}(\bar{\varphi})>L_{u}(\underline{\varphi}) \cdot{ }^{57}$ As in the text, this clustered equilibrium is unique when inequality is sufficiently large, i.e. $\widetilde{\beta}=\frac{\beta_{u}}{\beta_{s}}<\frac{\varphi}{\overline{\underline{\varphi}}}$. Hence the role of self-regulatory function of changes in self-esteem, as in (15), is to lead to the emergence and to insure the stability of moral standards. Finally notice that the result on the non monotonicity of redistribution do not depends on the role of self-esteem for labor supply since it is induced by the increasing bias against the poor in clustered equilibria.

\footnotetext{
${ }^{57}$ In fact in this case a clustered equilibrium with $\varphi_{u}=\bar{\varphi}, \varphi_{s}=\varphi$ and $L_{u}(\bar{\varphi})>L_{s}(\varphi)$ can also be sustained. This equilibrium, however, disappears when inequality is sufficiently large, that is if $\widetilde{\beta}<\frac{\varphi}{\bar{\varphi}}$.
} 


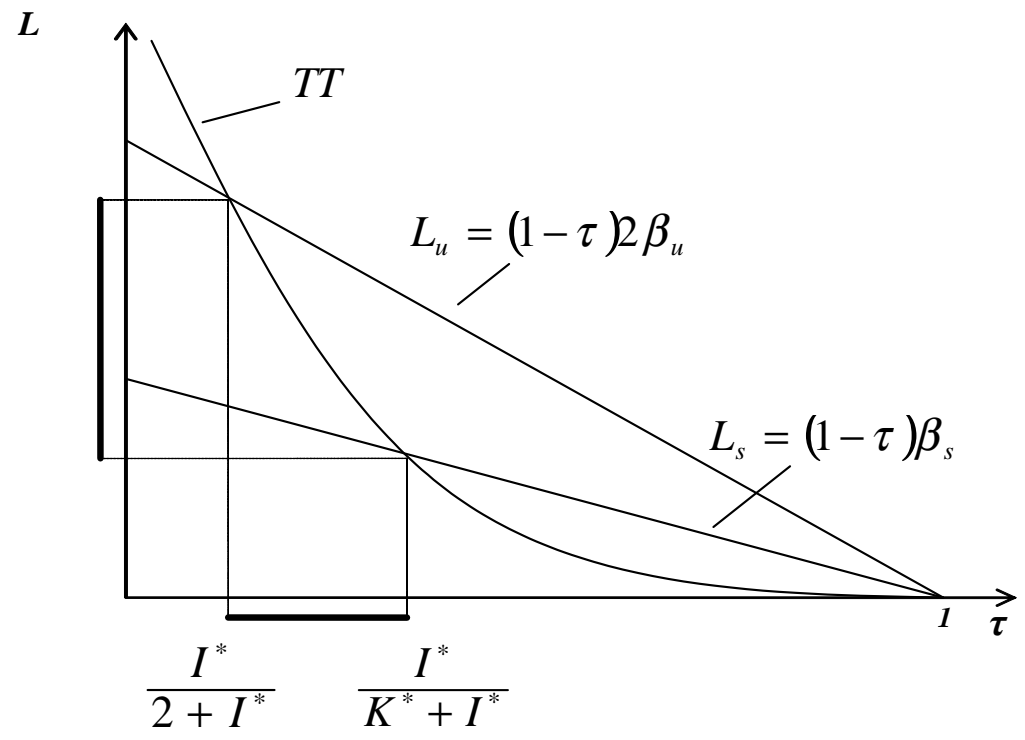

Figure 1: Cohesive Stationary Equilibria

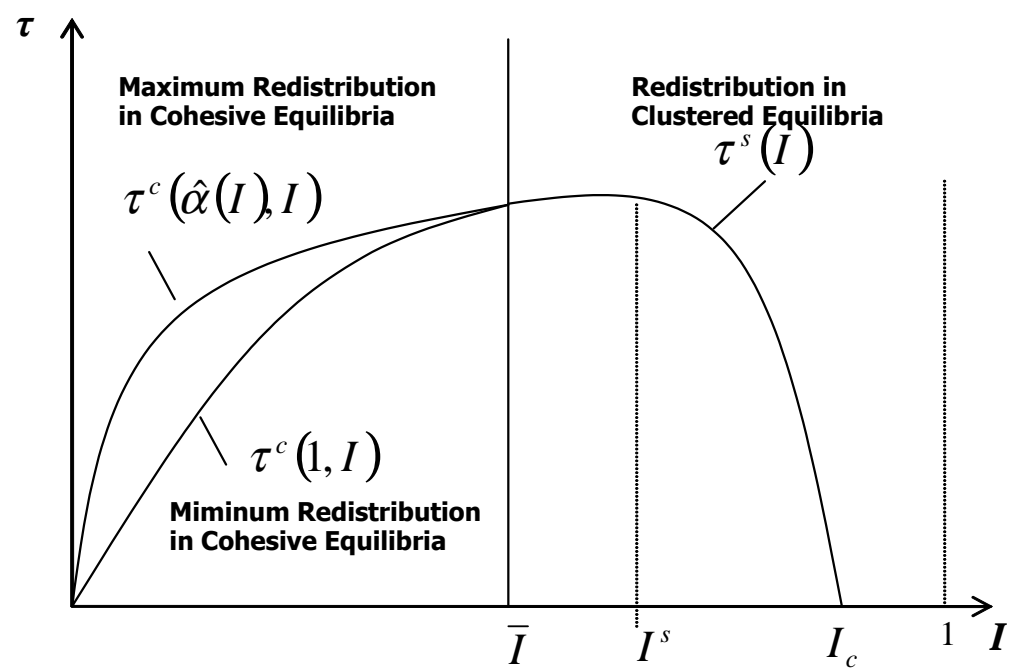

Figure 2: Inequality, Social Cohesion and Redistribution 


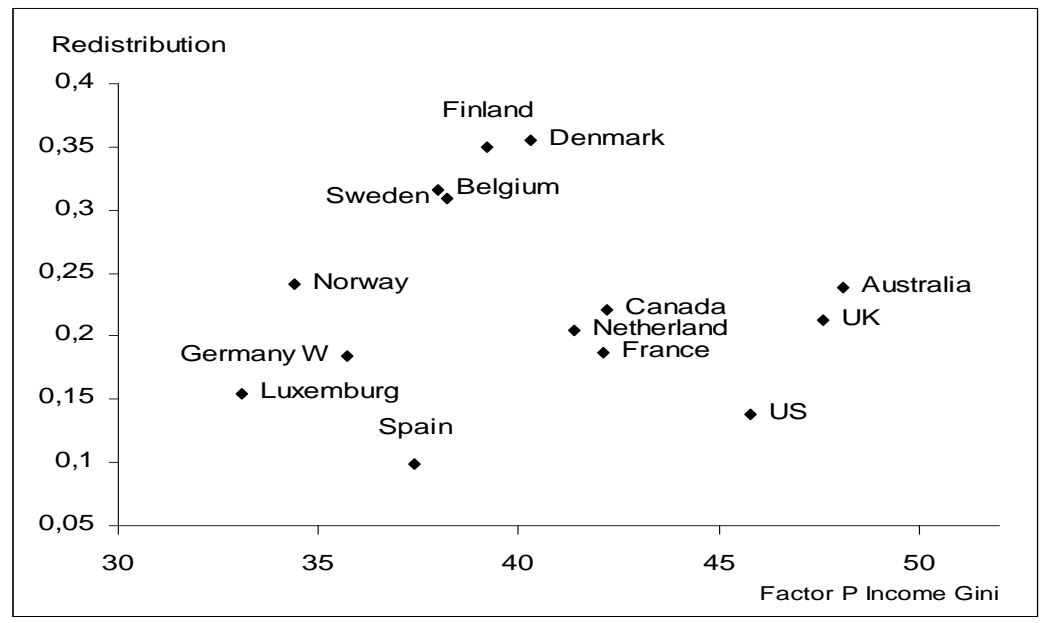

Figure 3: Factor Income Inequality and Redistribution

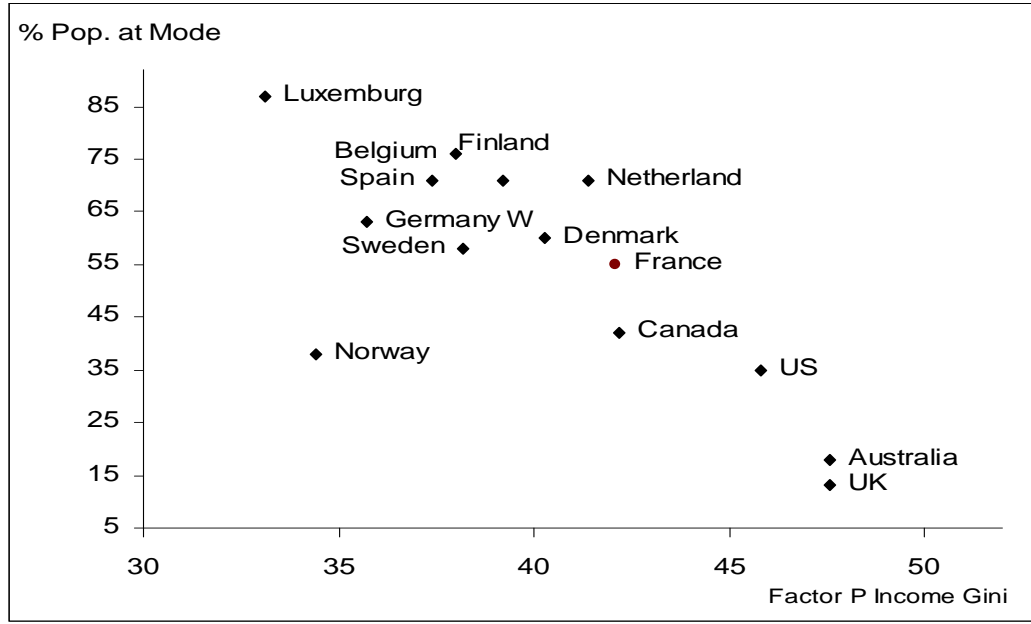

Figure 4: Factor Income Inequality and Dispersion in Hours Work 


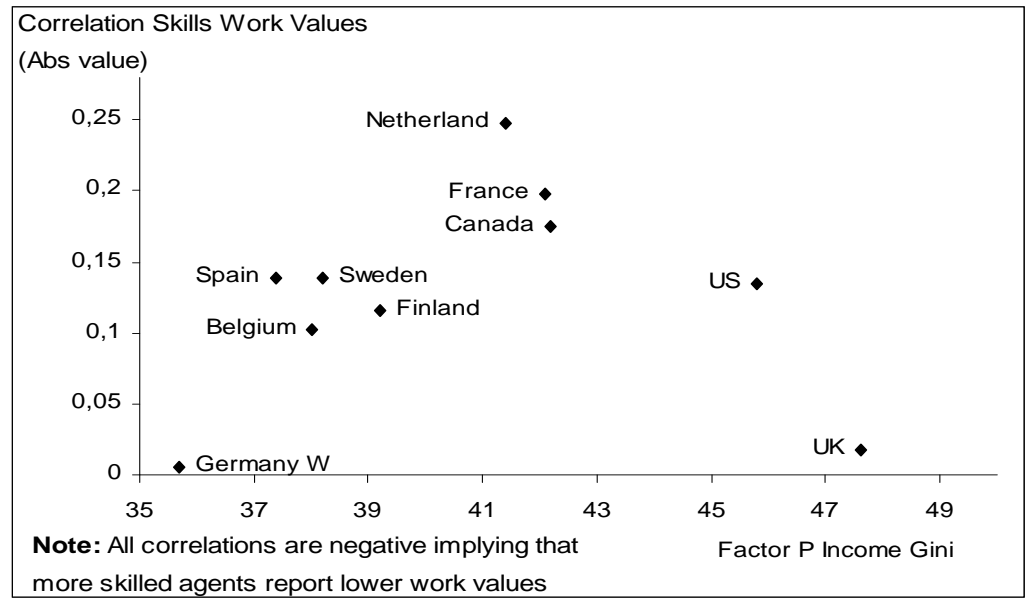

Figure 5: Correlation between Skills/Work Values and Factor Income Inequality

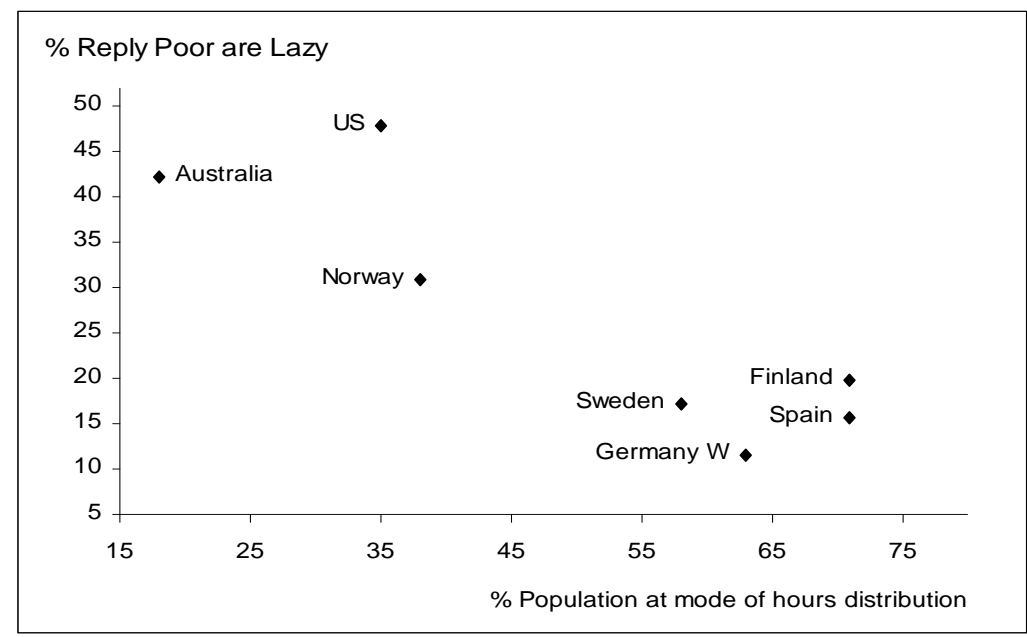

Figure 6: Perception of Poor as Lazy and Dispersion in Hours Work 